\title{
Combined retrieval of Arctic liquid water cloud and surface snow properties using airborne spectral solar remote sensing
}

\author{
André Ehrlich ${ }^{1}$, Eike Bierwirth ${ }^{1, a}$, Larysa Istomina ${ }^{2}$, and Manfred Wendisch ${ }^{1}$ \\ ${ }^{1}$ Leipzig Institute for Meteorology (LIM), University of Leipzig, Leipzig, Germany \\ ${ }^{2}$ Institute of Environmental Physics, University of Bremen, Bremen, Germany \\ anow at: PIER-ELECTRONIC GmbH, Nassaustr. 33-35, 65719 Hofheim-Wallau, Germany \\ Correspondence to: André Ehrlich (a.ehrlich@uni-leipzig.de)
}

Received: 16 February 2017 - Discussion started: 14 March 2017

Revised: 30 June 2017 - Accepted: 31 July 2017 - Published: 4 September 2017

\begin{abstract}
The passive solar remote sensing of cloud properties over highly reflecting ground is challenging, mostly due to the low contrast between the cloud reflectivity and that of the underlying surfaces (sea ice and snow). Uncertainties in the retrieved cloud optical thickness $\tau$ and cloud droplet effective radius $r_{\text {eff,C may arise from uncertainties in }}$ the assumed spectral surface albedo, which is mainly determined by the generally unknown effective snow grain size

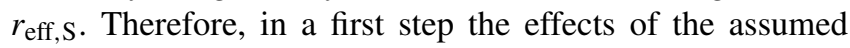
snow grain size are systematically quantified for the conventional bispectral retrieval technique of $\tau$ and $r_{\text {eff,C }}$ for liquid water clouds. In general, the impact of uncertainties of $r_{\text {eff, }}$ is largest for small snow grain sizes. While the uncertainties of retrieved $\tau$ are independent of the cloud optical thickness and solar zenith angle, the bias of retrieved $r_{\text {eff,C }}$ increases for optically thin clouds and high Sun. The largest deviations between the retrieved and true original values are found with $83 \%$ for $\tau$ and $62 \%$ for $r_{\text {eff,C. }}$.

In the second part of the paper a retrieval method is presented that simultaneously derives all three parameters $(\tau$, $\left.r_{\text {eff,C }}, r_{\text {eff,S }}\right)$ and therefore accounts for changes in the snow grain size. Ratios of spectral cloud reflectivity measurements at the three wavelengths $\lambda_{1}=1040 \mathrm{~nm}$ (sensitive to $r_{\text {eff,S }}$ ), $\lambda_{2}=1650 \mathrm{~nm}$ (sensitive to $\tau$ ), and $\lambda_{3}=2100 \mathrm{~nm}$ (sensitive to $r_{\text {eff,C }}$ ) are combined in a trispectral retrieval algorithm. In a feasibility study, spectral cloud reflectivity measurements collected by the Spectral Modular Airborne Radiation measurement sysTem (SMART) during the research campaign Vertical Distribution of Ice in Arctic Mixed-Phase Clouds (VERDI, April/May 2012) were used to test the retrieval procedure. Two cases of observations above the Canadian Beau-
\end{abstract}

fort Sea, one with dense snow-covered sea ice and another with a distinct snow-covered sea ice edge are analysed. The retrieved values of $\tau, r_{\text {eff,C }}$, and $r_{\text {eff,S }}$ show a continuous transition of cloud properties across snow-covered sea ice and open water and are consistent with estimates based on satellite data. It is shown that the uncertainties of the trispectral retrieval increase for high values of $\tau$, and low $r_{\text {eff, }}$ but nevertheless allow the effective snow grain size in cloud-covered areas to be estimated.

\section{Introduction}

During boreal winter, $15 \%$ of the Earth's surface is covered by snow and sea ice (Vaughan et al., 2013), while clouds cover roughly two-thirds of the globe (Boucher et al., 2013). Both snow and clouds considerably increase the reflected solar radiation at the top of the atmosphere and therefore are essential for determining the Earth's radiative energy budget. Changes in ice, snow, and cloud cover are both the result and cause of climate warming in Arctic areas (Wendisch et al., 2017). However, while snow and sea ice exhibit considerable seasonal variation, clouds usually vary on shorter timescales and smaller spatial scales. Therefore, continuous observations of cloud and snow properties are important. Commonly, satellite remote sensing techniques are applied to monitor the relevant radiative properties of clouds and snow, such as cloud optical thickness, cloud droplet effective radius, snow cover, effective snow grain size, and soot concentration (e.g. Stephens and Kummerow, 2007; Painter et al., 2009; Zege et al., 2011; Platnick et al., 2017). 
In polar regions clouds cover large areas of snow, glaciers, and sea ice, which complicates the retrieval of their properties because the contrast between these bright surfaces and the clouds is low. At wavelengths typically used to retrieve cloud properties from solar spectral reflectivity measurements, the optical properties of clouds and snow are similar. Therefore, cloud retrieval algorithms utilize observations at wavelengths larger than $1000 \mathrm{~nm}$ where the snow albedo is lower. Measurements at $1500 \mathrm{~nm}$ wavelength, where snow strongly absorbs solar radiation, were used by Krijger et al. (2011) and Gao et al. (1998) to improve the cloud detection above snow surfaces. Cloud optical thickness and droplet effective radius were successfully retrieved above snow surfaces by selecting a channel combination of the retrieval algorithm in the near-infrared spectral region. For example the combination of the 1640 and $2130 \mathrm{~nm}$ band was used for the Moderate Resolution Imaging Spectroradiometer (MODIS), while a combination of the 1240 and $1640 \mathrm{~nm}$ band was applied for the Visible Infrared Imaging Radiometer Suite (VIIRS) (Platnick, 2001; King et al., 2004; Platnick et al., 2013).

However, the cloud reflectivity in this spectral range is also affected by changes in the spectral albedo of the snow surface (Wiscombe and Warren, 1980). The smaller the snow grains, the higher the surface albedo and the more the radiation is reflected by the surface. Therefore, the retrieval of cloud properties (optical thickness and droplet effective radius) over snow surfaces requires a precise assumption of the effective snow grain size below the clouds. Snow grain size varies temporally and spatially due to precipitation that decreases the snow grain size and because of the snow metamorphism that slowly increases the snow grain size (e.g. Flanner and Zender, 2006; Jacobi et al., 2010). In polar areas, the effective snow grain size typically ranges between $50 \mu \mathrm{m}$ for freshly fallen snow and $1000 \mu \mathrm{m}$ for aged snow (Wiebe et al., 2013). This snow metamorphism changes the broadband surface albedo by $14 \%$ from 0.89 to 0.77 . Most of this effect on albedo occurs at longer wavelengths at which the imaginary part of the refractive index of ice is high. Therefore, the decrease of the spectral albedo at $1300 \mathrm{~nm}$ is enhanced to $65 \%$ from 0.75 to 0.26 (Dang et al., 2016). In midlatitude areas the snow metamorphism is often accelerated by higher temperatures, which can lead to effective snow grain sizes of up to $3000 \mu \mathrm{m}$ causing an even stronger reduction of snow albedo (Singh, 2001; Derksen et al., 2014). Also white sea ice that is not covered by snow and not water saturated, i.e. dry white ice, can be characterized by larger effective snow grain sizes (Malinka et al., 2016). This is because at wavelengths larger than $1000 \mathrm{~nm}$ the albedo of white sea ice is lower than that of snow-covered sea ice. However, most cloud retrieval techniques do not consider a variation of the snow and sea ice albedo. For the MODIS cloud product Collection 6, a fixed surface albedo of 0.03 for both wavelength bands (1640 and $2130 \mathrm{~nm}$ ) is assumed over sea ice or snowcovered areas (King et al., 2004). In contrast to land surfaces, no spatial or temporal changes in the snow and sea ice albedo are considered.

Uncertainties of the surface albedo affect the retrieval of cloud optical properties, which has been shown by Rolland and Liou (2001), Platnick (2001), and Fricke et al. (2014). These studies focus on optically thin clouds over typical land surfaces with a high variability of the spectral albedo at wavelengths below $1 \mu \mathrm{m}$. For an optically thin cirrus, Fricke et al. (2014) estimated retrieval uncertainties of up to $50 \%$ for the ice crystal effective radius depending on cloud optical thickness. Rolland and Liou (2001) showed that the retrieval uncertainties of thin cirrus can be reduced by $20 \%$ for optical thickness and by $45 \%$ for ice crystal effective radius when a reasonable estimate of the surface albedo is applied. For snow-covered areas, only the difference between snow/sea ice albedo and the albedo of the sea ice-free ocean has been addressed in improved retrieval algorithms (Platnick, 2001). So far, no estimates of the effect of a varying snow albedo on cloud retrievals have been reported in the literature.

For satellite observations of spectral solar radiation, retrieval algorithms that provide effective snow grain size have been developed by Painter et al. (2009) and Zege et al. (2011). These techniques exploit the dependence of spectral snow albedo and reflectivity and effective snow grain size. A larger effective snow grain size increases the photon path length within the snow grain and hence the probability that radiation is absorbed in the snow layer, which reduces the snow albedo. As thin snow layers already dominate the radiation reflection by the surface, the retrievals are most sensitive to the uppermost snow layer and, thus, changes by precipitation, snow metamorphism, and the concentration of impurities are of utmost importance (Wiebe et al., 2013; Libois et al., 2013). The retrieval methods by Painter et al. (2009) and Zege et al. (2011) use these sensitivities and estimate the black carbon concentration in the snow, which mostly affects the visible range of the spectral albedo. Unfortunately, these satellite retrievals of snow properties do not cover the full spatial and temporal evolution of effective snow grain size and snow albedo as they are limited to cloud-free areas (Lyapustin et al., 2009; Zege et al., 2011). However, cloud layers in polar regions are often observed to prevail for several days (Herman and Goody, 1976; Shupe et al., 2006, 2011). In such a case, the cloud retrieval may suffer from an outdated assumption of snow or sea ice albedo. A correct solution is only possible if snow and cloud properties are determined in combination as suggested in this paper.

Measurements of spectral cloud reflectivity have been successfully applied to distinguish between liquid and ice water clouds (Pilewskie and Twomey, 1987; Ehrlich et al., 2008; LeBlanc et al., 2015). Making use of differences in the spectral absorption of liquid water and ice, which are manifested in the spectral shape of the cloud reflectivity, several indices are defined to identify the dominant cloud phase. Similarly, this study makes use of the different spectral absorption characteristics for snow surfaces and liquid water clouds to re- 


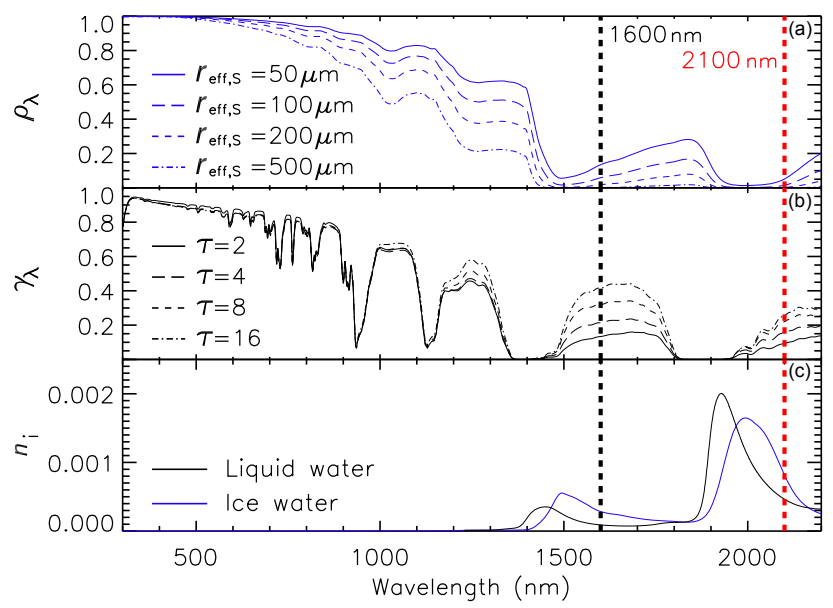

Figure 1. Comparison of spectral snow albedo $\rho_{\lambda}$ (a) and cloud reflectivity $\gamma_{\lambda}$ (b) for different $r_{\text {eff,S }}$ and $\tau$, respectively. Cloud reflectivity has been simulated for clouds with $r_{\text {eff,C }}=10 \mu \mathrm{m}$ that are located above a snow surface with $r_{\text {eff, }}=100 \mu \mathrm{m}$. The imaginary part of the refractive index of ice and liquid water is given in panel (c). Vertical lines indicate the wavelength used in the bispectral cloud retrieval.

trieve cloud and snow properties simultaneously. To illustrate the need for such retrieval methods, the uncertainties due to uncertainties in the assumed snow albedo on the retrieval of cloud properties will be quantified in Sect. 2. The new retrieval method will be introduced in Sects. 3 and 4 including the identification of the most suitable wavelengths applied in the retrieval as well as the forward simulations of cloud reflectivity. In a feasibility study in Sect. 5, the algorithm that is limited to cases of liquid water clouds is applied to two specific cases, which have been observed by airborne spectral cloud reflectivity measurements during the field campaign Vertical Distribution of Ice in Arctic Clouds (VERDI) over the Canadian Beaufort Sea in 2012.

\section{Uncertainties of bispectral cloud retrieval over snow}

\subsection{Forward simulations}

Based on radiative transfer simulations the impact of uncertainties of the snow albedo on the retrieved cloud properties is quantified. The spectral solar reflectivity above a liquid water cloud layer was simulated using the DISORT 2 radiative transfer solver embedded in the library for radiative transfer (libRadtran, Emde et al., 2016). A solar zenith angle of $63^{\circ}$ representative of Arctic conditions around spring was chosen in the simulations. Typical Arctic boundary layer liquid water clouds located between 200 and $500 \mathrm{~m}$ altitude were assumed. Cloud optical thickness $\tau$ was varied from 1 to 20 and cloud droplet effective radius $r_{\text {eff,C }}$ between 2 and $25 \mu \mathrm{m}$. For all clouds, simulations with different surface albedo covering effective snow grain sizes $r_{\text {eff,S }}$ between 10 and $800 \mu \mathrm{m}$ were performed. The spectral snow albedo $\rho_{\lambda}$ was calculated with the parameterization by Zege et al. (2011) using the refractive index of ice by Warren and Brandt (2008) and a form factor $A=5.8$. This form factor is adopted from Zege et al. (2011) and accounts for the non-sphericity of snow grains; it represents a mixture of randomly oriented hexagonal plates and columns with rough surfaces. This mixture and therefore the form factor $A$ may vary depending on the local snow properties. However, an uncertainty of $A$ can be attributed to an uncertainty in the effective snow grain size as both properties have the same spectral impact on the snow reflection characteristics, such as spectral albedo. Snow impurities by black carbon were neglected as the absorption by black carbon is typically limited to wavelengths less than $1000 \mathrm{~nm}$ (e.g. Warren and Wiscombe, 1980; Liou et al., 2014) that are not used in cloud retrieval over snow surfaces. A set of calculated spectral snow albedo $\rho_{\lambda}$ is presented in Fig. 1a, which illustrates the decrease of $\rho_{\lambda}$ with increasing values of $r_{\text {eff,S }}$ for wavelengths $\lambda>1000 \mathrm{~nm}$ where the imaginary part of the refractive index of ice is high (Fig. 1c).

The simulated upward nadir radiance $I_{\lambda}$ and downward irradiance $F_{\lambda}$ were converted into spectral cloud reflectivity $\gamma_{\lambda}$ defined by

$\gamma_{\lambda}=\frac{\pi \cdot I_{\lambda}}{F_{\lambda}}$.

In Fig. $1 \mathrm{~b}$ a set of $\gamma_{\lambda}$ for typical values of $\tau$ between 2 and 16 is shown for a fixed cloud effective droplet size of $r_{\text {eff,C }}=10 \mu \mathrm{m}$ and a typical effective snow grain size of $r_{\text {eff, }}=100 \mu \mathrm{m}$. The simulations illustrate that $\tau$ impacts $\gamma_{\lambda}$ primarily at wavelengths larger than $1000 \mathrm{~nm}$ where the snow albedo is lower than 0.8 , while lower wavelengths are less sensitive to $\tau$.

Based on the simulated cloud reflectivities, which are used as synthetic measurements, the commonly used bispectral cloud retrieval algorithm was applied to obtain cloud optical thickness and droplet effective radius. This retrieval method is similar to the cloud product of MODIS (Platnick, 2001). The retrieval uses the different dependencies of $\gamma_{1600 \mathrm{~nm}}$ (less-absorbing wavelength) and $\gamma_{2100 \mathrm{~nm}}$ (highabsorbing wavelength) on cloud optical thickness and cloud droplet effective radius and basically follows the method by Nakajima and King (1990).

The bispectral retrieval grid obtained from the simulated cloud reflectivities is presented in Fig. 2 for three effective snow grain sizes: 50,100 , and $500 \mu \mathrm{m}$. The grids significantly differ and show a considerable snow grain size effect, especially for low values of $\gamma_{1600 \mathrm{~nm}}$, while at higher reflectivities the grids tend to converge. The reflectivity $\gamma_{2100 \mathrm{~nm}}$ is less affected by changes of $r_{\text {eff, }}$ as the snow albedo is close to zero for $r_{\mathrm{eff}, \mathrm{S}}>100 \mu \mathrm{m}$ (see Fig. 1). As the retrieval of $\tau$ is strongly linked to $\gamma_{1600 \mathrm{~nm}}$, the effect of the snow albedo on the retrieved $\tau$ is obvious. However, the non-rectangular shape of the grids indicates that both reflectivities are coupled to both cloud parameters and, thus, also the retrieved 


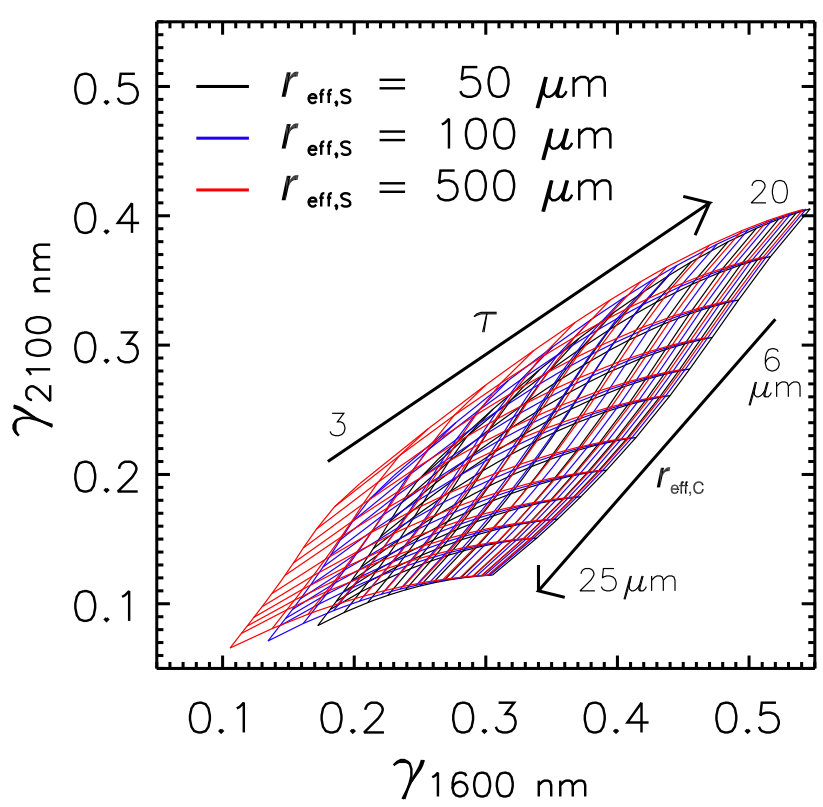

Figure 2. Bispectral retrieval grids of cloud top nadir reflectivity $\gamma_{1600 \mathrm{~nm}}$ and $\gamma_{2100 \mathrm{~nm}}$ assuming three different effective snow grain sizes $r_{\text {eff, }}$ of 50,100 , and $500 \mu \mathrm{m}$. The simulated reflectivities cover cloud optical thickness $\tau$ between 3 and 20 and cloud droplet effective radius $r_{\text {eff,C }}$ between 6 and $25 \mu \mathrm{m}$.

$r_{\text {eff,C }}$ will be affected by changes in the effective snow grain size.

\subsection{Snow grain size effect on cloud retrieval results}

For liquid water cloud retrievals obtained over snow surfaces with unknown grain size, the snow grain size effect on uncertainties of retrieval results was quantified. Therefore, synthetic measurements obtained from the retrieval forward simulations as introduced in Sect. 2.1 are applied. For each synthetic measurement defined by $\tau, r_{\mathrm{eff}, \mathrm{C}}$, and $r_{\mathrm{eff}, \mathrm{S}}$, a set of retrievals assuming different values of effective snow grain sizes were performed. The purpose of this exercise is to use the synthetic measurement (for which the original $r_{\mathrm{eff}, \mathrm{S}}$ is known), and start the retrieval assuming $r_{\text {eff, }}$ is not known. The impact of these wrong assumptions about the retrieved cloud properties is then quantified.

In Fig. 3a and b the retrieval results are compared to the original cloud properties for synthetic measurements calculated with an original effective snow grain size of $50 \mu \mathrm{m}$, but retrieved from forward simulations assuming a effective snow grain size of $200 \mu \mathrm{m}$ (crosses). The asterisks symbols in Fig. 3a and b indicate the opposite case: originally $r_{\mathrm{eff}, \mathrm{S}}=200 \mu \mathrm{m}$ is used to produce the synthetic measurement and then $r_{\text {eff, }}=50 \mu \mathrm{m}$ is assumed in the retrieval of the cloud properties. While Fig. 3a shows retrieved $\tau$ for different $r_{\text {eff,C }}$ indicated by the colour code, Fig. $3 \mathrm{~b}$ presents retrieved $r_{\text {eff,C }}$ for clouds of different $\tau$ also indicated by a colour code.

Assuming $r_{\mathrm{eff}, \mathrm{S}}$ to be larger than originally present, the retrieved $\tau$ is systematically overestimated because the surface albedo is underestimated in this case (larger $r_{\mathrm{eff}, \mathrm{S}}$ assumes lower snow albedo at $1600 \mathrm{~nm}$; see also Fig. 1). If $r_{\text {eff,S }}$ is underestimated (surface albedo overestimated) the snow grain size effect is inverted, leading to an underestimation of $\tau$. This is in agreement with the general surface albedo sensitivity of cloud retrieval as discussed by Rolland and Liou (2001) and Fricke et al. (2014). For the case presented in Fig. 3, the snow grain size effect, expressed by the percentage deviation of the retrieved from the original true value, ranges up to $83 \%$ for low optical thickness $\tau=3$.

The results for $\tau$ do not significantly depend on $r_{\text {eff,C }}$. By contrast, the uncertainties introduced in the retrieval of $r_{\text {eff, }}$ strongly depend on $\tau$ as illustrated in Fig. 3b. Especially for clouds of low optical thickness, the retrieved $r_{\text {eff,C }}$ is significantly overestimated/underestimated when the effective snow grain size is assumed to be higher/lower than originally present. The snow grain size effect ranges up to $62 \%$ for optically thin clouds $(\tau=3)$ with small $r_{\text {eff, } \mathrm{C}}=5 \mu \mathrm{m}$. If larger effective snow grain sizes are assumed, the absorption observed in $\gamma_{1600 \mathrm{~nm}}$ is overestimated while $\gamma_{2100 \mathrm{~nm}}$ is almost unchanged. This combination leads to an estimate of too low $r_{\text {eff,C }}$ in the retrieval.

While the retrieval of $\tau$ is always biased due to uncertainties of $r_{\text {eff, }}$, independently of $r_{\text {eff, }}$, no snow grain size effect is observed for the retrieval of $r_{\text {eff,C }}$ in the case of $\tau$ larger than about 10. For optically thick clouds, the high extinction of incoming radiation inside the cloud layer leads to a low amount of radiation that reaches the surface and interacts with the snow and is transmitted back to the cloud top. In this case the interaction of radiation with the surface can be neglected and therefore the surface albedo, or the assumption of $r_{\mathrm{eff}, \mathrm{S}}$, is not relevant.

The cases discussed in Fig. 3a and $\mathrm{b}$ represent the typical range of $r_{\text {eff,S }}$ from 50 to $200 \mu \mathrm{m}$ as expected in Arctic areas for snow surfaces. However, white sea ice and snow cover in midlatitudes may exhibit a higher variability leading to larger uncertainties. Therefore, Fig. $3 \mathrm{c}$ and d summarize the snow grain size effect on the retrieval of $\tau$ (Fig. 3c) and $r_{\text {eff,C }}$ (Fig. 3d) for a set of combinations of assumed and original $r_{\text {eff, }}$. A typical cloud with low optical thickness of $\tau=4$ and $r_{\text {eff,C }}=10 \mu \mathrm{m}$ (green circles in Fig. 3a and b) was analysed. The red dots indicate the cases that are included in Fig. 3a and $b$.

The over- and underestimation of $r_{\mathrm{eff}, \mathrm{S}}$ leads to almost symmetric effects for the clouds investigated here. The maximum snow grain size effect on the retrieval of $\tau$ covered by the simulations leads to a retrieval of $\tau=2$ or $\tau=6$, significantly deviating from the original value of $\tau=4$. Compared to the original $r_{\mathrm{eff}, \mathrm{C}}=10 \mu \mathrm{m}$ the results for $r_{\mathrm{eff}, \mathrm{C}}$ range between 6 and $13 \mu \mathrm{m}$. The effects are most pronounced when either smaller effective snow grain sizes are assumed or origi- 
(a)

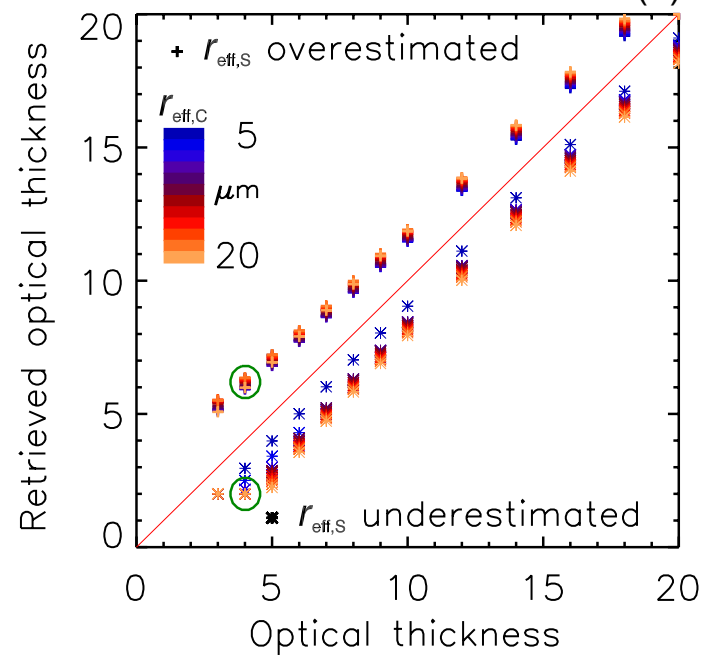

(c)

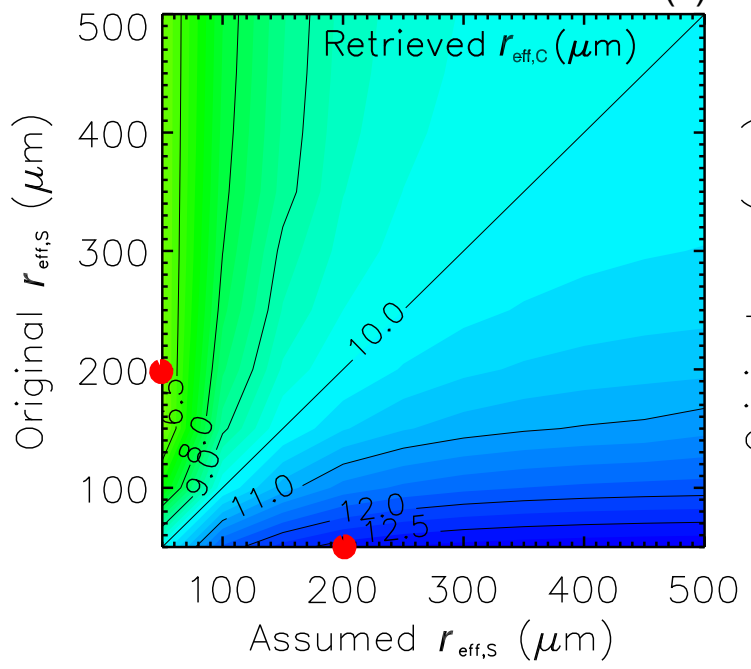

(b)

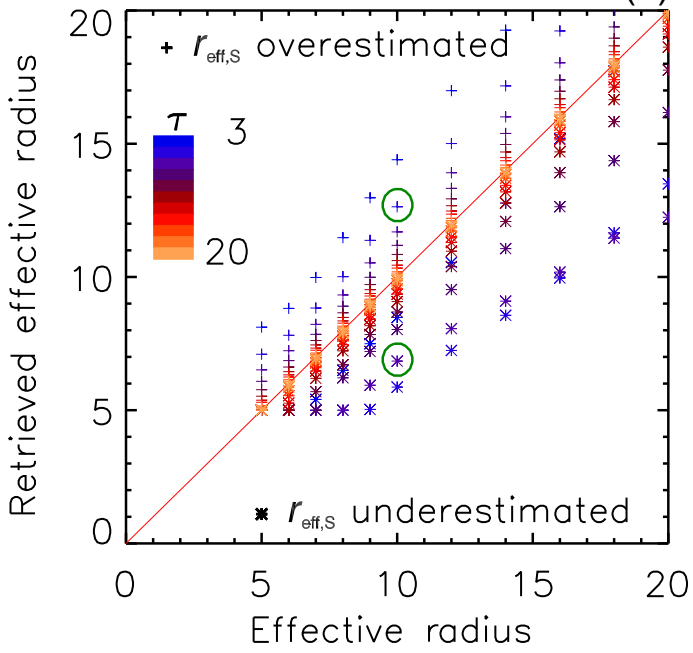

(d)

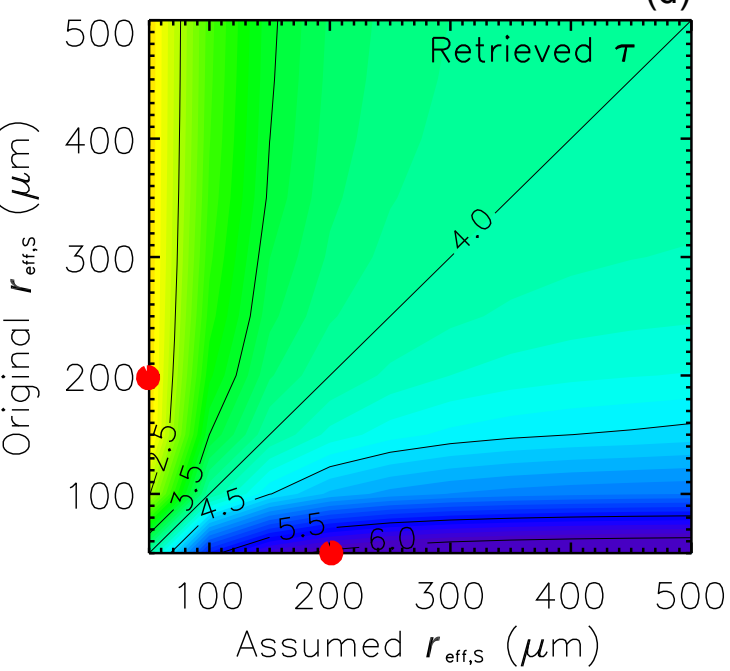

Figure 3. Comparison of synthetically retrieved $\tau(\mathbf{a}, \mathbf{c})$ and $r_{\text {eff, }}(\mathbf{b}, \mathbf{d})$ with the original parameter value. Calculations in (a) and (b) are performed, assuming a larger effective snow grain size of $r_{\mathrm{eff}, \mathrm{S}}=200 \mu \mathrm{m}$ instead of the original $r_{\text {eff, }}=50 \mu \mathrm{m}$ (crosses) and a smaller effective snow grain size of $r_{\text {eff, }}=50 \mu \mathrm{m}$ instead of the original $r_{\text {eff,S }}=200 \mu \mathrm{m}$ (asterisks). In (c) and (d) all combinations of assumed and original $r_{\text {eff, }}$ are analysed for a specific cloud of $\tau=4$ and $r_{\text {eff,C }}=10 \mu \mathrm{m}$. The red dots in (c) and (d) indicate the cases included in (a) and (b), where results for the same cloud are indicated by green circles.

nally present; e.g. $50 \mu \mathrm{m}$ is assumed but $300 \mu \mathrm{m}$ is present, or $300 \mu \mathrm{m}$ is assumed and $50 \mu \mathrm{m}$ is present. Similar mismatches between assumed and original $r_{\text {eff,S }}$ at larger grain sizes, e.g. $300 \mu \mathrm{m}$ and $500 \mu \mathrm{m}$, cause lower errors in the retrieved $\tau$

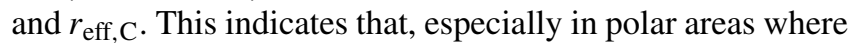
snow grain sizes are typically smaller, the retrieval biases due to a wrong assumption of $r_{\mathrm{eff}, \mathrm{S}}$ cannot be neglected.

The numbers presented here were obtained for a solar zenith angle of $\theta_{0}=63^{\circ}$. For simulations with different solar zenith angles in the range between 45 and $80^{\circ}$ similar grain size effects are observed. In general, the magnitude of the grain size effect of $\tau$ does not significantly change with $\theta_{0}$. However, for low Sun (large $\theta_{0}$ ), the grain size effect on the retrieved $r_{\text {eff,C }}$ was slightly reduced, while for higher Sun, small $\theta_{0}$, the effects increase. This is caused by the increased probability that radiation interacts with the surface in the case of a decreasing solar zenith angle.

\section{Separating the spectral signatures of liquid water clouds and snow}

In cases where liquid water clouds are located above a snow surface, the spectral differences of absorption of solar radiation by snow (ice water) and clouds (liquid water) as illustrated in Fig. 1 can be used to separate the surface and cloud contributions to the reflected radiation above the cloud. In ad- 


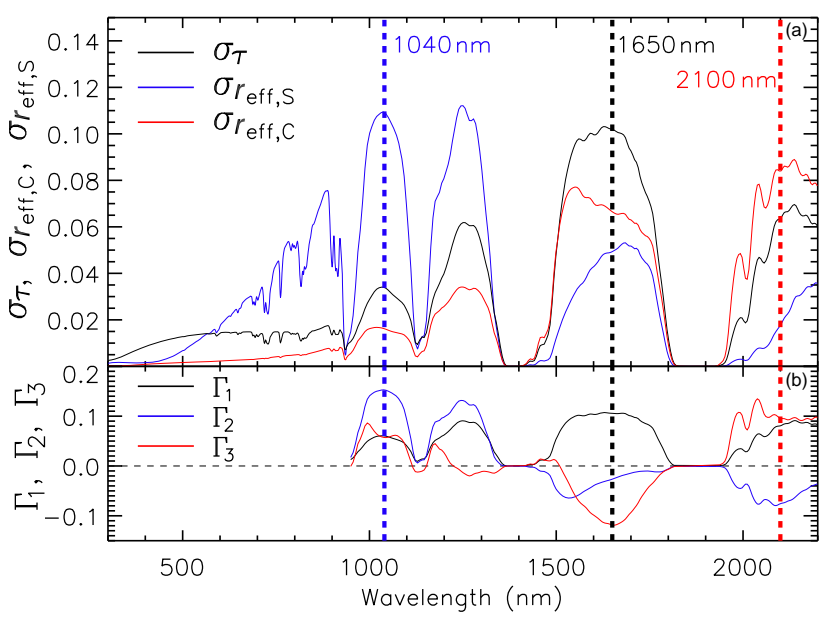

Figure 4. Mean standard deviations of spectral cloud reflectivity $\sigma_{\tau}, \sigma_{r_{\text {eff,C }}}$, and $\sigma_{r_{\text {eff,S }}}$ with respect to a single cloud or snow parameter $\tau, r_{\text {eff,C }}$, and $r_{\text {eff, S }}$ calculated for the sets of radiative transfer simulations (a). The first three spectral weights $\Gamma_{1}, \Gamma_{2}$, and $\Gamma_{3}$ of a principle component analysis are given in (b).

dition, the different size ranges of cloud droplets (typically $r_{\text {eff,C }}<20 \mu \mathrm{m}$ ) and snow grains (typically $r_{\text {eff, }}>50 \mu \mathrm{m}$ ) amplify these spectral signatures of ice and liquid water. The photon path length inside large snow grains is prolonged, which leads to stronger absorption and a lower reflectivity compared to the smaller liquid water droplets.

Using the cloud reflectivity simulations introduced in Sect. 2, two metrics are derived to identify wavelengths that are most sensitive to only one single parameter, either $\tau$, $r_{\mathrm{eff}, \mathrm{C}}$ or $r_{\mathrm{eff}, \mathrm{S}}$. The first parameter $\sigma$ is provided by the mean standard deviation of $\gamma_{\lambda}$ with respect to a single parameter $\tau, r_{\text {eff,C }}$, and $r_{\text {eff,S. }}$. For example, for each cloud, a standard deviation of all simulations with different $r_{\text {eff, }}$ was calculated. $\sigma_{r_{\mathrm{eff}, \mathrm{S}}}$ is then derived by averaging these standard deviations for all different clouds. The second parameter is the spectral weighting of a principle component analysis (PCA) applied to the full set of simulations. Corresponding to the cloud and snow parameters changed in the simulations, the spectral weights $\Gamma_{1}, \Gamma_{2}$, and $\Gamma_{3}$ of the first three principle components are found to be associated with $\tau\left(\Gamma_{1}\right), r_{\text {eff,C }}$ $\left(\Gamma_{2}\right)$, and $r_{\text {eff, }}\left(\Gamma_{3}\right)$.

Both metrics are shown in Fig. 4 for $\tau\left(\sigma_{\tau}\right.$ and $\left.\Gamma_{1}\right)$, for $r_{\text {eff,C }}\left(\sigma_{r_{\text {eff,C }}}\right.$ and $\left.\Gamma_{2}\right)$, and for $r_{\text {eff,S }}\left(\sigma_{r_{\text {eff, }}}\right.$ and $\left.\Gamma_{3}\right)$. The results are presented for a solar zenith angle of $\theta_{0}=63^{\circ}$ but are applicable to larger and smaller $\theta_{0}$. The three calculated functions of $\sigma$ show that the maximum variability of the cloud reflectivity with respect to the three parameters is located in different spectral regions. While $r_{\text {eff,S }}$ mostly affects the cloud reflectivity at wavelengths between 930 and $1350 \mathrm{~nm}, \tau$ introduces high standard deviations in the wavelength range of $1500-1800 \mathrm{~nm}$. However, this spectral range is also influenced by $r_{\text {eff,C }}$ with $\sigma_{r_{\text {eff,C }}}$ showing values only moderately lower than $\sigma_{\tau}$. Values of similar magnitude are observed for $\sigma_{r_{\text {eff,C }}}$ at wavelengths larger then $2000 \mathrm{~nm}$. In this spectral range $r_{\text {eff,C }}$ is the dominating parameter determining the cloud reflectivity.

Similar spectral patterns result from the PCA, which delivers the spectral weights $\Gamma_{1}, \Gamma_{2}$, and $\Gamma_{3}$, are presented in Fig. 4b. A comparison with the three calculated $\sigma$ in Fig. 4b reveals that $\Gamma_{1}$ can be associated with $\tau, \Gamma_{3}$ with $r_{\text {eff,C }}$ and $\Gamma_{2}$ with $r_{\text {eff,S }}$. The major contribution to $\Gamma_{1}$ is located in the wavelength range $930-1350 \mathrm{~nm}$ dominated by the changes in snow albedo, $r_{\text {eff,s. }}$. The impact of $\tau$ is spectrally neutral, showing a similar magnitude of $\Gamma_{1}$ in all analysed wavelengths except for the water vapour absorption bands. By contrast, wavelengths above $1500 \mathrm{~nm}$ contribute most to the weight of the third principle component $\Gamma_{3}$, but with opposite signs for the $1500-1800 \mathrm{~nm}$ and the $2000-2200 \mathrm{~nm}$ wavelength range.

It has to be mentioned that these sensitivities might change for different scenarios assumed in the radiative transfer simulations, e.g. different solar zenith angle, cloud altitude, profile of cloud droplet size, or aerosol concentration. Similarly, the use of subsamples of the full cloud and snow parameter range investigated here might change the derived values. However, the general separation of the three parameters by different spectral ranges will not essentially differ.

\section{Trispectral retrieval algorithm}

\subsection{Selected wavelengths and radiance-ratios}

Based on the spectral footprint of $\tau, r_{\mathrm{eff}, \mathrm{C}}$ and $r_{\mathrm{eff}, \mathrm{S}}$ in the cloud reflectivity, a trispectral retrieval algorithm is proposed to derive the three cloud and snow parameter simultaneously. In this way, the conventional bispectral cloud retrieval was extended by a third measurement at a wavelength sensitive to $r_{\text {eff, }}$, which adds the information on the snow grain size. Compared to retrieval algorithms that rely on a fixed assumption of $r_{\text {eff,S }}$, this new trispectral approach reduces the uncertainty of the retrieved cloud parameters. In particular, measurements at $\lambda_{1}=1040 \mathrm{~nm}$ which are most sensitive to $r_{\mathrm{eff}, \mathrm{S}}$, $\lambda_{2}=1650 \mathrm{~nm}$ most sensitive to $\tau$, and $\lambda_{3}=2100 \mathrm{~nm}$ most sensitive to $r_{\text {eff,C }}$ were chosen in the retrieval algorithm.

In the new trispectral retrieval algorithm, the radianceratio method introduced by Werner et al. (2013), Brückner et al. (2014), and LeBlanc et al. (2015) was applied. A normalization with the cloud reflectivity at $\lambda_{0}=860 \mathrm{~nm}$ was chosen. The corresponding ratios $R_{1}, R_{2}$, and $R_{3}$ are calculated as 
Table 1. Standard deviation of the reflectivity ratios $R_{1}, R_{2}$, and $R_{3}$ with respect to one of the three cloud and snow parameters $\tau, r_{\mathrm{eff}, \mathrm{C}}$, and $r_{\text {eff,S }}$.

\begin{tabular}{rrrr}
\hline & $r_{\text {eff, }}$ & $\tau$ & $r_{\text {eff,C }}$ \\
\hline$R_{1}$ & $\mathbf{0 . 0 7 4}$ & 0.039 & 0.015 \\
$R_{2}$ & 0.065 & $\mathbf{0 . 1 4 5}$ & 0.088 \\
$R_{3}$ & 0.054 & 0.056 & $\mathbf{0 . 1 2 1}$ \\
\hline
\end{tabular}

$$
\begin{gathered}
R_{1}=\frac{\gamma_{\lambda_{1}}}{\gamma_{\lambda_{0}}}, \quad R_{2}=\frac{\gamma_{\lambda_{2}}}{\gamma_{\lambda_{1}}}, \quad R_{3}=\frac{\gamma_{\lambda_{3}}}{\gamma_{\lambda_{2}}}, \\
\text { with } \lambda_{0}=860 \mathrm{~nm}, \lambda_{1}=1040 \mathrm{~nm}, \\
\lambda_{2}=1650 \mathrm{~nm}, \text { and } \lambda_{3}=2100 \mathrm{~nm} .
\end{gathered}
$$

The normalizations additionally reduce the uncertainties of the retrieval by cancelling potential biases in the radiometric calibration of the measurements. Except for $\lambda_{1}$, all wavelengths that were chosen for the algorithm are covered by the satellite imagers MODIS and VIIRS. To apply the algorithm to global observations by these instruments, $\lambda_{1}$ can be exchanged by the $1240 \mathrm{~nm}$ wavelength band where cloud reflectivity is still most sensitive to $r_{\text {eff, }}$.

Similarly to Sect. 3, the mean standard deviation $\sigma$ with respect to $\tau, r_{\text {eff,C }}$, and $r_{\text {eff,S }}$ was calculated for the three reflectivity ratios. Table 1 shows $\sigma$ for all possible parameter combinations. The higher $\sigma$, the more sensitive $R_{1}, R_{2}$, and $R_{3}$ are with respect to changes of an individual cloud or snow parameter. One ratio with significantly higher $\sigma$ is found for each parameter, $\tau, r_{\text {eff,C }}$, and $r_{\text {eff,s. }}$. For the cloud optical thickness the highest $\sigma=0.145$ is found for $R_{2}$, which is almost twice as high as the sensitivity of $R_{1}$ and $R_{3}$. Similarly, $R_{1}$ shows the highest sensitivity to $r_{\text {eff,S }}$ and $R_{3}$ the highest $\sigma$ for $r_{\text {eff,S }}$ and $r_{\text {eff,C }}$ with $\sigma=0.074$ and $\sigma=0.121$, respectively. This indicates that $R_{1}, R_{2}$, and $R_{3}$ are well suited to separate the information of $\tau, r_{\text {eff,C }}$, and $r_{\text {eff,S }}$ from spectral reflectivity measurements.

\subsection{Retrieval grid}

The set of cloud reflectivity simulations introduced in Sect. 2 served for the forward simulations (solar zenith angle of $63^{\circ}$, liquid water cloud layer between 200 and $500 \mathrm{~m}$ ). The simulated grids of $R_{1}, R_{2}$, and $R_{3}$ used for the trispectral retrieval are presented in Fig. 5. While Fig. 5d shows the full 3dimensional (3-D) grid covering $\tau=1-20, r_{\text {eff,C }}=5-25 \mu \mathrm{m}$ and $r_{\text {eff, }}=25-800 \mu \mathrm{m}$, Fig. 5a-c presents two-dimensional projections of reflectivity ratios with one parameter being fixed. In Fig. 5a, $r_{\text {eff, }}$ is set to $50 \mu \mathrm{m}$ (black) and $500 \mu \mathrm{m}$ (red), while in Fig. 5b $r_{\text {eff,C }}$ is fixed at $5 \mu \mathrm{m}$ (black) and $16 \mu \mathrm{m}$ (red) and in Fig. 5c $\tau$ is fixed to values of 4 (black) and 16 (red). The simulated grids show that the individual lines almost align orthogonally for wide ranges of the sim- ulated parameter space. The different surfaces do not overlap. This indicates that the three chosen ratios $R_{1}, R_{2}$, and $R_{3}$ separate the influence of the three parameters $\tau, r_{\text {eff,C }}$, and $r_{\text {eff, }}$ on the cloud reflectivity and allow a retrieval of the cloud and snow parameters leaving few ambiguities. Only for $r_{\text {eff, }}$ lower than $50 \mu \mathrm{m}$ is the grid more narrow, as seen in Fig. 5d (uppermost black grid) and Fig. 5a (black grid). Such a narrow grid increases the uncertainty of the retrieved $\tau$ and $r_{\text {eff,C }}$, especially for clouds of low optical thickness. This grid characteristic is caused by the higher surface albedo of snow for small values of $r_{\mathrm{eff}, \mathrm{S}}$, which reduces the contrast between cloud and snow surface for the wavelengths used to calculate the three ratios. However, a retrieval of cloud and snow properties is still possible in these ranges if the measurement uncertainties are sufficiently small. A more general quantification of the retrieval sensitivities and uncertainties can be derived by optimal estimation techniques, which is, however, beyond of the scope this paper.

Ambiguities appear in the retrieval for small cloud droplet effective radii of $r_{\text {eff,C }}<5 \mu \mathrm{m}$ (not shown in Fig. 5). In that case the absorption of cloud droplets is weak and the cloud reflectivity is similar to a cloud with larger $r_{\text {eff,C }}$ but smaller $\tau$. Therefore, all solutions with $r_{\text {eff,C }}<5 \mu \mathrm{m}$ were excluded from the retrieval.

\subsection{Adjustments and uncertainty estimation}

The retrieval algorithm was additionally adjusted to Arctic conditions where open water and ice floes can occur in close proximity. First, the algorithm determines whether the measurements are obtained over snow-covered sea ice or open water surfaces. Even in the case of cloud-covered scenes, the border between sea ice and open water is clearly discernable in the cloud top reflectivity as shown by Schäfer et al. (2015). A surface with a high albedo always enhances the upward radiance above a cloud even in the case of optically thick clouds. Therefore, a fixed threshold of cloud reflectivity $\gamma\left(\lambda_{0}\right)>0.65$ at a wavelength of $860 \mathrm{~nm}$ is applied to distinguish measurements obtained above snow or white sea ice from those over open water. This value may need to be adjusted for conditions of different solar zenith angles or clouds with higher optical thickness. The threshold assumes that the field of view of the radiance measurement (pixel size) is fully covered by a single surface type that is reasonable for airborne measurements. However, for satellite observations with typically larger pixel sizes, scenes dominated by broken sea ice might be misclassified.

If the cloud reflectivity at $860 \mathrm{~nm}$ is below the threshold, an open water surface is assumed. In that case the bispectral retrieval following the radiance ratio approach of Werner et al. (2013) is applied. Cloud reflectivities $\gamma\left(\lambda_{2}\right)$ and the reflectivity ratio $R_{3}=\gamma\left(\lambda_{3}\right) / \gamma\left(\lambda_{2}\right)$ are used to retrieve $\tau$ and $r_{\text {eff,C. If }} \gamma\left(\lambda_{0}\right)$ is above the threshold, a snow surface is assumed. Then the measurements are converted into the three 

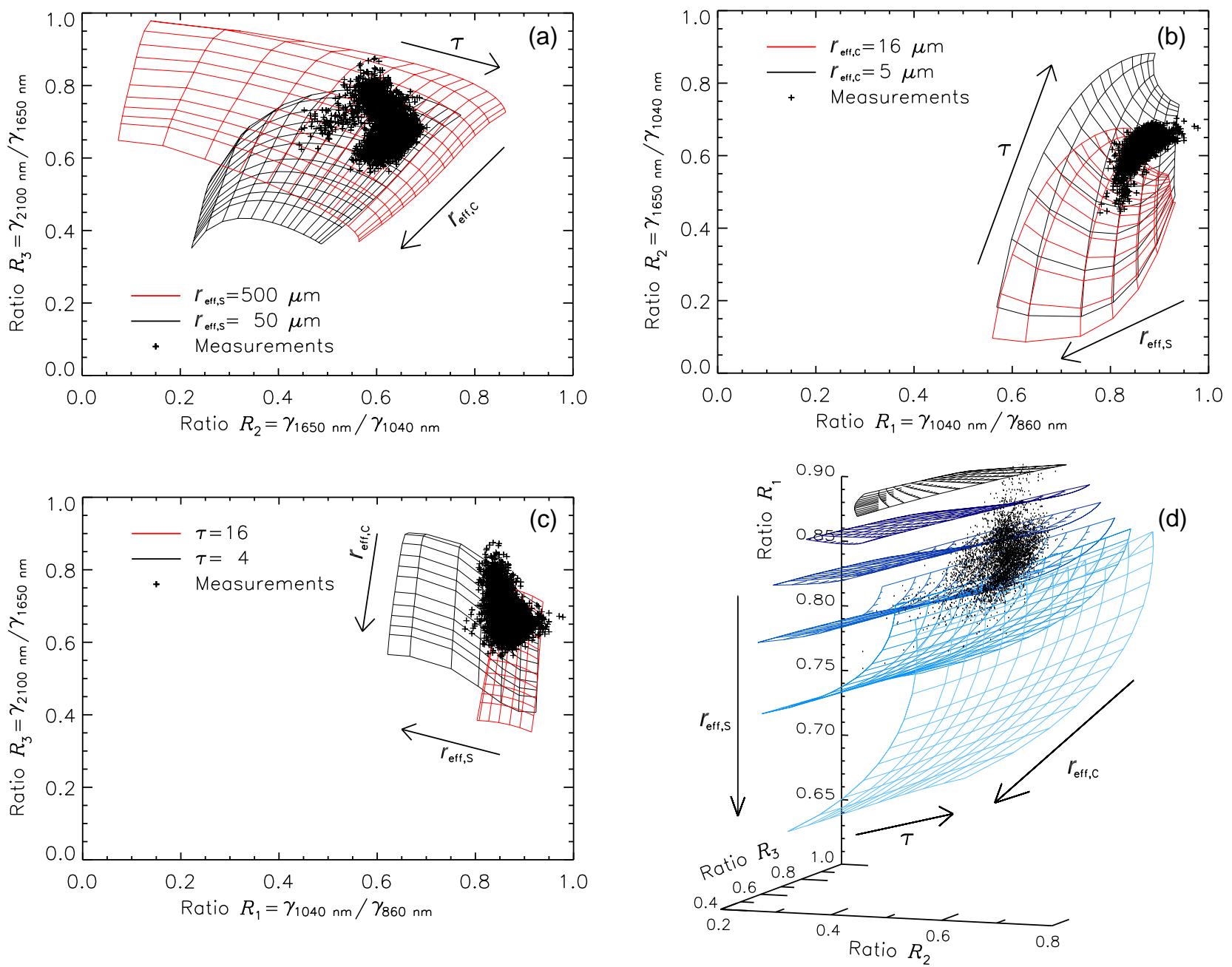

Figure 5. Three-dimensional retrieval grid using the ratios $R_{1}, R_{2}$, and $R_{3}$ obtained from simulations covering $\tau=1-20, r_{\text {eff,C }}=5-25 \mu \mathrm{m}$ and $r_{\text {eff, }}=25-800 \mu \mathrm{m}$. Panels (a)-(c) show each two selected two-dimensional section of the retrieval grid, while (d) covers the full 3-D grid. Representative measurements obtained during VERDI (29 April 2012) are represented by black dots.

reflectivity ratios $R_{1}, R_{2}$, and $R_{3}$ and interpolated to the 3-D grid of simulated values introduced in Sect. 4.2.

However, 3-D radiative effects in the vicinity of sea ice edges significantly influence the reflected radiation and bias the retrieved cloud properties (Schäfer et al., 2015). Depending on cloud and surface geometry, this effect is important up to several kilometres from the ice edge. Therefore, measurements collected close to sea ice edges have been removed from the analysis.

The retrieval uncertainties are estimated considering the measurement errors of the reflectivity ratio and assuming a Gaussian distribution of the errors. In this case the uncertainties can be expressed by their double standard deviation $2 \sigma$. The retrieval is operated for varying each ratio, $R_{1}, R_{2}$, and $R_{3}$, separately by adding and subtracting $2 \sigma$. This procedure results in six solutions for the trispectral retrieval over snow surfaces and four solutions for the bispectral retrieval over open water. This set of solutions is sufficient to represent the full solution space of the Gaussian distributed measurement uncertainties. The median of these solutions is used as the retrieval result of $\tau, r_{\mathrm{eff}, \mathrm{C}}$, and $r_{\mathrm{eff}, \mathrm{S}}$, while the standard deviation of all solutions quantifies the retrieval uncertainty $\Delta \tau$, $\Delta r_{\text {eff,C }}$, and $\Delta r_{\text {eff,s. }}$.

Independent of these uncertainties caused by the measurements, systematic errors due to the assumptions in the forward simulations are considered. Currently, the retrieval algorithm is limited to liquid water clouds and, therefore, may suffer if the cloud contains ice. In the Arctic, mixed-phase clouds that are dominated by a liquid water layer at cloud top are frequent (Mioche et al., 2015). In this case, the retrieval may provide unrealistic cloud properties as the ice crystals absorb solar radiation at similar wavelengths to the snow surface. The absorption by the ice crystals may add to the absorption by the snow surface and bias the results. 
Furthermore, limitations of the snow albedo parameterization by Zege et al. (2011) applied in the forward simulations may introduce biases in the retrieved $r_{\mathrm{eff}, \mathrm{s}}$. The parameterization assumes a fixed snow grain shape quantified by the form factor $A=5.8$. Typical values of $A$ range from 5.1 for fractals to 6.5 for spheres. For a retrieval of snow grain size in cloud-free conditions, the snow grain shape implies uncertainties in the retrieved effective snow grain size up to $25 \%$. However, as discussed by Zege et al. (2011), the reflection characteristics of the snow, in particular the spectral albedo, are not affected at wavelengths used by the retrieval algorithm. Both properties $A$ and $r_{\text {eff, }}$ change the snow albedo with similar spectral patterns, which allows the uncertainty of $A$ to be attributed as an uncertainty of $r_{\text {eff,s. Therefore, the }}$ retrieved cloud properties are independent of the assumption of $A$.

This emphasizes that the retrieved $r_{\text {eff, }}$ always has to be considered as an effective quantity. It represents the snow grain size that has to be used in the specific albedo parameterization (fixed form factor $A$ ) to provide the snow albedo which is most representative for the measurements. Spatial or temporal differences of the retrieved $r_{\text {eff,S }}$ may result either from a change of the geometric size of the snow grains or from changes in the snow grain shape quantified by the form factor.

\section{Application to airborne measurements}

Airborne spectral solar radiation measurements were collected with the Spectral Modular Airborne Radiation measurement sysTem (SMART) during the airborne research campaign VERDI. A total of 16 research flights was conducted in April/May 2012 with the Polar 5 aircraft operated by Alfred-Wegener Institute for Marine and Polar Research (AWI) over the Canadian Beaufort Sea, which was partly covered with snow-covered sea ice.

SMART measured the spectral solar radiance reflected in nadir direction $\left(2.1^{\circ}\right.$ field of view $)$ and downward spectral irradiance with grating spectrometers covering the wavelength range between 350 and $2200 \mathrm{~nm}$ (Wendisch et al., 2001; Ehrlich et al., 2008). From both quantities cloud reflectivity $\gamma$ was calculated using Eq. (1). SMART was calibrated radiometrically, spectrally, and geometrically in the laboratory.

The uncertainties of the measurements mostly originate from the radiometric calibration given by the uncertainty of the applied radiation source (traceable to the standards of the National Institute of Standards and Technology, NIST) and the signal-to-noise ratio that differs with wavelength due to the sensitivity of the spectrometers. By calculating the ratios $R_{1}, R_{2}$, and $R_{3}$ used in the retrieval algorithm, calibration uncertainties are partly cancelled out. For example a bias in the radiometric calibration will affect cloud reflectivities at different wavelengths to the same degree, but does not influence the ratios. Altogether, assuming typical measurements of clouds above snow, a $2 \sigma$ uncertainty of $6 \%$ was estimated for $R_{1}$, while for $R_{2}$ and $R_{3}, 4$ and $12 \%$ uncertainties were considered. For the retrieval of clouds over open water, where $\gamma\left(\lambda_{2}\right)$ and the reflectivity ratio $R_{3}$ are used, the darker surface (lower signal and lower signal to noise ratio) leads to uncertainties in the observations of $9 \%$ for $\gamma\left(\lambda_{2}\right)$ and $13 \%$ for $R_{3}$.

Two 30 min sections from observations on 29 April (Case I) and 17 May 2012 (Case II) were selected to test the retrieval algorithm. In both cases a wide area close to the coastline was covered by stratiform boundary layer clouds. While for Case I the cloud top, defined by the boundary layer inversion, reached altitudes of up to $700 \mathrm{~m}$, persistent subsidence driven by anticyclonic conditions lead to a low cloud top of $200 \mathrm{~m}$ in Case II. During the remote sensing observations of these clouds, the Polar 5 aircraft flew at an altitude of about $3000 \mathrm{~m}$. The flight tracks and the sections of the flight selected for a detailed analysis are included in Figs. 8 and 10.

For the application of the retrieval to the measurements, it has to be considered that a pure snow surface is assumed in the forward simulations. Although a snow thickness of $2 \mathrm{~cm}$ will be sufficient to neglect the variation of snow albedo with snow thickness (Warren, 2013), this constraint might not be valid for observations over sea ice with leads or melt ponds. The research flights of VERDI have been performed almost exclusively over the partly sea-ice-covered Beaufort Sea. For the two cases, observations have been selected in which the surface conditions are close to the required pure snow surface. However, potential effects by leads, melt ponds, or snow-free sea ice are discussed for the individual cases.

Cloud microphysical in situ measurements on board of Polar 5 were use to validate the retrieved $r_{\text {eff,C. A Cloud Droplet }}$ Probe (CDP) provided size-resolved cloud particle concentrations in the size range from 2.5 to $46 \mu \mathrm{m}$ and corresponding $r_{\text {eff,C }}$ (Klingebiel et al., 2015). Using only one aircraft, the in situ and remote sensing measurements had been performed subsequently. For both investigated cases, I and II, the remote sensing flight legs were flown first. Roughly $1 \mathrm{~h}$ later the in situ measurements were obtained at the same location following the flight track of the remote sensing sequence. Due to the stable meteorological conditions, changes in the cloud properties with time are expected to be small which allows for a comparison of in situ and remote sensing data. A reference to validate the retrieved snow grain size is not available because no ground-based measurements on the sea ice have been conducted during VERDI.

\subsection{Case I - 29 April 2012}

The observations in this case were collected exclusively over snow-covered sea ice and obtained between 16:54 and 17:21 UTC with a solar zenith angle of $63^{\circ}$. The retrieved cloud and snow properties are presented in Fig. 6. Cloud optical thickness ranged between $\tau=6$ at the beginning and $\tau=15$ at the end of the flight leg. $r_{\text {eff,C }}$ also shows a ten- 


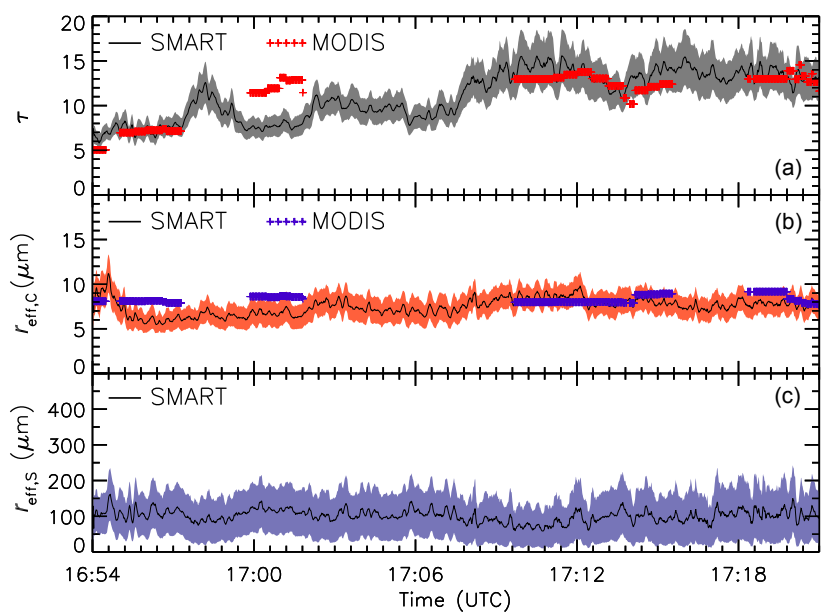

Figure 6. Time series of cloud optical thickness $\tau$ (a), cloud droplet effective radius $r_{\text {eff,C }}$ (b) and effective snow grain size $r_{\text {eff,S }}(\mathbf{c})$ retrieved from SMART measurements for Case I on 29 April 2012. Uncertainties of the retrieved properties are indicated by dark shaded areas. When available, results of the MODIS cloud product are given for $\tau$ and $r_{\text {eff, } C}(5 \times 5$ pixel average $)$.

dency of increasing values between 6 and $9 \mu \mathrm{m}$, while $r_{\mathrm{eff}, \mathrm{S}}$ remained almost constant at values around $100 \mu \mathrm{m}$. In situ cloud microphysical measurements of $r_{\text {eff,C }}$ had been obtained along the same flight track, about $1 \mathrm{~h}$ after the remote sensing measurements. At the cloud top, two derived vertical profiles show $r_{\text {eff,C }}$ between 6 and $7.5 \mu \mathrm{m}$, which is in the range of the retrieval results.

The retrieval uncertainties are indicated by the shaded areas in Fig. 6. In the first part of the time series, up to 17:07 UTC, the retrieval uncertainties are lowest for $\tau$ with about $\Delta \tau \pm 1$, and range at $\Delta r_{\text {eff, }} \pm 1.5 \mu \mathrm{m}$ for $r_{\text {eff, }}$, and $\Delta r_{\text {eff, }} \pm 60 \mu \mathrm{m}$ for $r_{\text {eff, }}$. In the second part of the time series, the retrieval uncertainty $\Delta \tau$ significantly increases. This correlates with the increase of the cloud optical thickness. Similarly, $\Delta r_{\text {eff,S }}$ shows a slight negative correlation with uncertainties being higher for low $\tau$. This is also reflected by the retrieval grids presented in Fig. 5. The grid spacing is narrower for larger $\tau$.

For all measurements, the behaviour of $\Delta \tau$ and $\Delta r_{\text {eff, }}$ S as functions of the retrieved $\tau$ and $r_{\text {eff, S }}$ is shown in Fig. 7. For $\Delta \tau$, values of $r_{\text {eff, }}$ are colour-coded in each data point, while for $\Delta r_{\text {eff, }}$ colours indicate $\tau$. Positive correlations are found for both parameters: the larger the retrieved $\tau$ or $r_{\mathrm{eff}, \mathrm{S}}$, the larger their uncertainties. For $\Delta \tau$ uncertainties are larger for small $r_{\text {eff,S }}$ (colour code in Fig. 7a). In this case, small $r_{\text {eff, }}$ increase the snow albedo and lower the contrast between clouds and snow surface at $\lambda=1650 \mathrm{~nm}$, which then becomes less sensitive to $\tau$. Similarly, $\Delta r_{\text {eff, }}$ depends on the retrieved $\tau$ (colour code in Fig. 7b), with higher uncertainties observed for large $\tau$. For high optical thickness the clouds begin to mask the surface, and information of the surface is lost
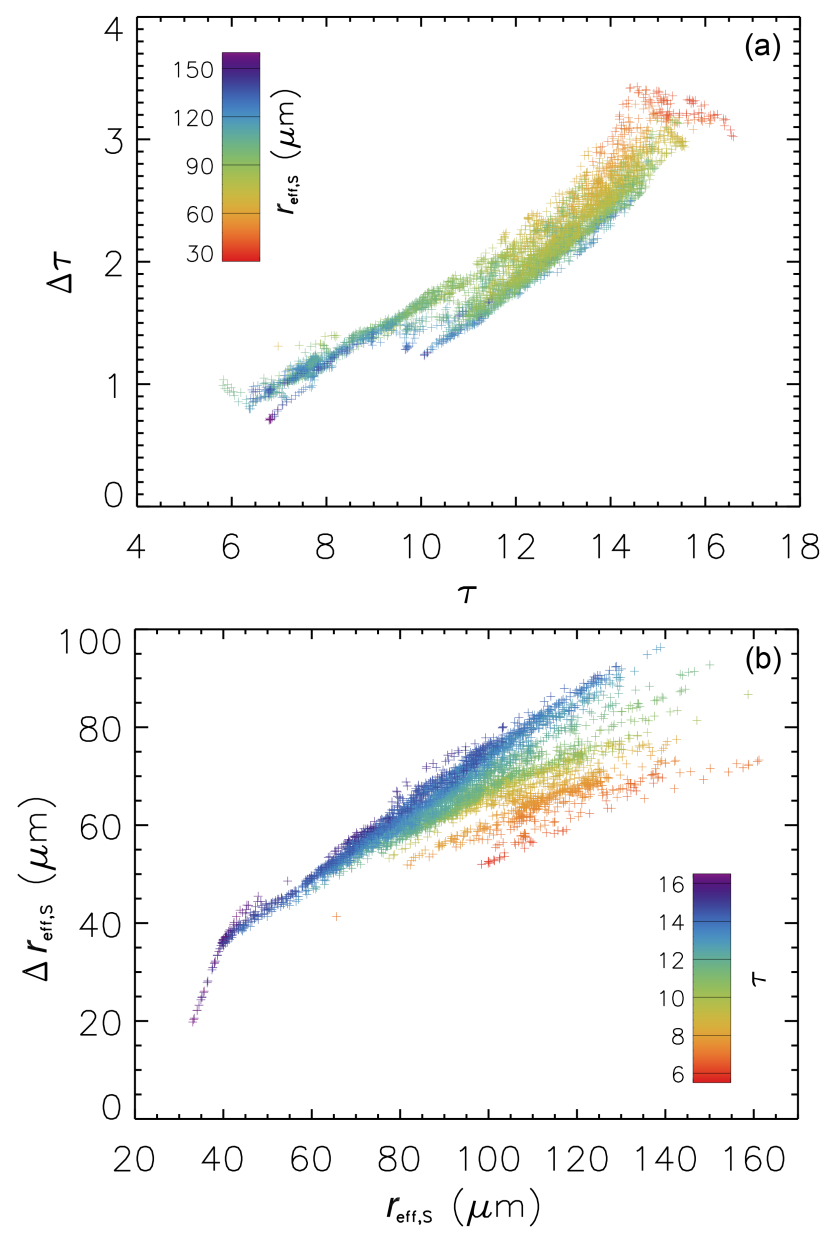

Figure 7. Uncertainties $\Delta \tau$ (a) and $\Delta r_{\text {eff, }}$ (b) as a function of retrieved $\tau$ and $r_{\text {eff, }}$. The single measurements are colour coded with $r_{\mathrm{eff}, \mathrm{S}}$ for (a) and $\tau$ for (b).

in the reflected radiation measured above cloud top leading to higher uncertainties of $r_{\text {eff, }}$. For $\Delta r_{\text {eff,C }}$, similar dependencies are obtained but with less spread; $\Delta r_{\text {eff, }}$ ranges between \pm 1.2 and $\pm 1.7 \mu \mathrm{m}$ (not shown here). $\Delta r_{\text {eff,C }}$ was found to increase slightly with decreasing $r_{\text {eff,S }}$ and increasing $r_{\text {eff,C. }}$.

The snow-covered sea ice below the clouds did have some open or only recently frozen leads, which were identified when Polar 5 flew below clouds after the remote sensing flight leg. From automatic photographs taken on board Polar 5, the proportion of leads was estimated to be lower than $5 \%$, which might explain some of the higher values observed in the retrieved time series of $r_{\mathrm{eff}, \mathrm{S}}$.

The retrieved cloud and snow properties were compared to satellite observations by MODIS (Wiebe et al., 2013). Figure 8 shows maps of cloud optical thickness $\tau$ (a), droplet effective radius $r_{\text {eff,C }}$ (b) and effective snow grain size $r_{\text {eff, }}$ (c) retrieved by MODIS. The flight track of Polar 5 is indicated by a black line and overlayed by the retrieval results of SMART. $\tau$ and $r_{\text {eff,C }}$ retrieved by MODIS along the flight 

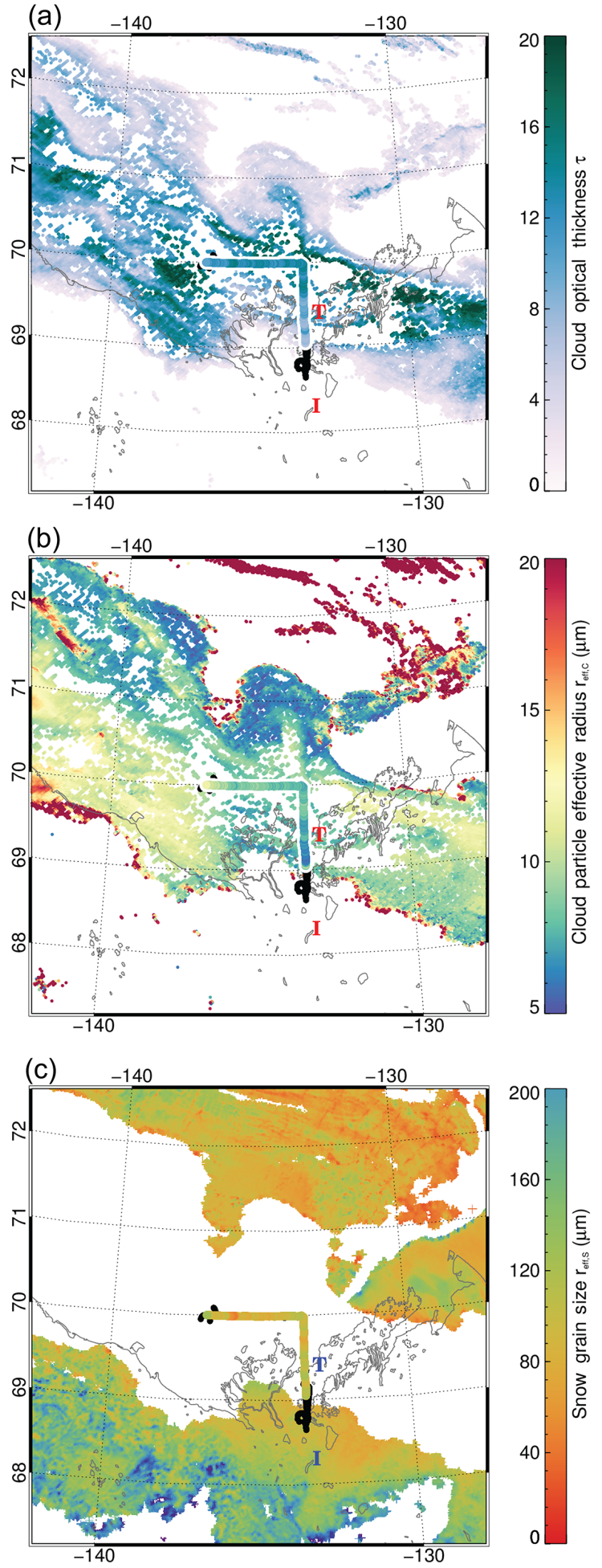

Figure 8. Cloud optical thickness $\tau$ (a), cloud droplet effective radius $r_{\text {eff,C }}$ (b) and effective snow grain size $r_{\text {eff,S }}$ (c) retrieved by MODIS and SMART for Case I on 29 April 2012. The total flight track is indicated by a black line and overlayed by the retrieval results of SMART. "I" and "T" mark the locations of Inuvik and Tuktoyaktuk. track are additionally included in Fig. 6. Cloud properties are obtained by the MODIS cloud product Collection 6 for observations over snow or sea ice using band 6 at $1640 \mathrm{~nm}$ and band 7 at $2130 \mathrm{~nm}$ (Platnick et al., 2017). The effective snow grain size is provided by the Snow Grain Size and Pollution amount (SGSP) retrieval algorithm by Zege et al. (2011). The SGSP is limited to cloud-free pixels and therefore does not show values below the clouds observed in the same image. For Case I, the Aqua overpass of 20:00 UTC was analysed. Although the MODIS scene was taken about $3 \mathrm{~h}$ after the airborne measurements, the stable cloud conditions allow a comparison. Snow grain sizes typically change over longer timescales, except when precipitation occurs. The weather station in Tuktoyaktuk close to the coastline did report light precipitation of snow grains but is not necessarily representative for the clouds over the Beaufort Sea. However, a direct comparison of $r_{\text {eff,S }}$ is not possible due to the missing data in cloudy pixels.

The MODIS cloud product in Fig. 8 shows $\tau$ and $r_{\text {eff,C }}$ in the same range as that retrieved from the airborne measurements. Note that here a longer time series is shown than presented in Fig. 6. This includes areas with snow-covered land surfaces, for which the retrieval can be applied assuming that the snow layer is sufficiently thick and the snow albedo is not affected by the underlying surface (Warren, 2013). At the southern edges of the cloud field, lower values of $\tau$ are observed by both MODIS and SMART. For $r_{\text {eff,C }}$ the values retrieved by SMART show the same tendency of lower $r_{\text {eff,C }}$ at the southern cloud edge and increasing $r_{\mathrm{eff}, \mathrm{C}}$ towards the western end of the flight track. For large areas of this cloud field the MODIS cloud product did not provide valid solutions, which illustrates the limits of the current cloud retrieval in Arctic regions.

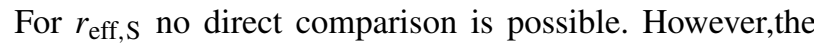
retrieval using measurements by SMART fills the gap of the cloudy areas not considered in the SGSP retrieval for MODIS. The retrieved $r_{\text {eff,S }}$ are in the same range as those observed by MODIS south and north of the cloud field and therefore are considered to be consistent with the SGSP product. Lower $r_{\text {eff,S }}$ were detected by MODIS at higher latitudes with some bias due to large leads in the sea ice that are imprinted in the retrieval results. At lower latitudes, the snow is strongly influenced by accelerated metamorphism processes due to higher temperatures and therefore exhibits larger $r_{\mathrm{eff}, \mathrm{S}}$.

\subsection{Case II - 17 May 2012}

For the second case, observations collected on a flight leg crossing a sea ice edge between 16:45 and 17:12 UTC were analysed. This transition allows for testing the consistency of the proposed retrieval algorithm for observations over snow and open water. Compared to Case I, the cloud altitude was lower with $200 \mathrm{~m}$ cloud top altitude indicating a thinner cloud layer. The time of day and solar zenith angle were almost identical to Case I. 


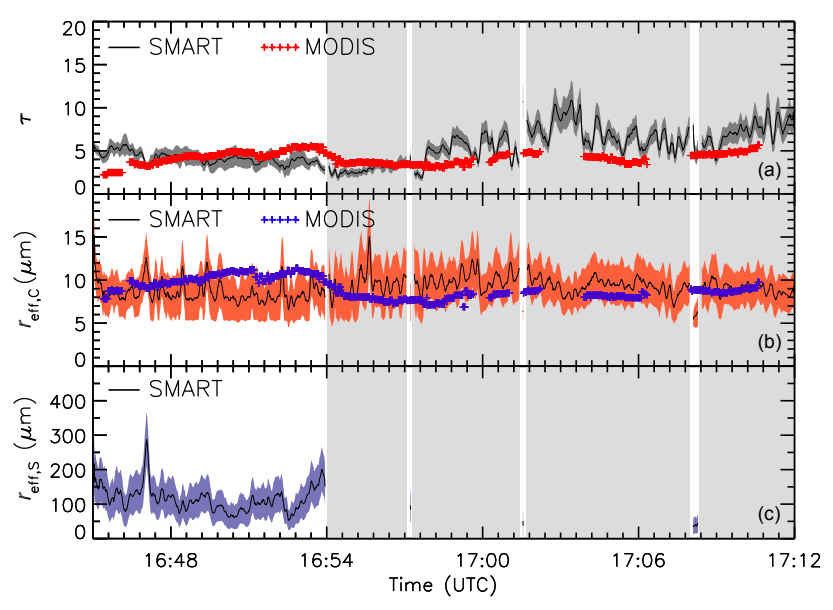

Figure 9. Same as Fig. 6 but for 17 May 2012. Non-shaded times indicate measurements above snow while for light-grey-shaded times the ocean was ice free.

The retrieved cloud and snow properties for Case II are presented in Fig. 9. Additionally, the light grey shaded time sections indicate measurements above the open ocean while during non-shaded times snow-covered sea ice was present below the clouds. As suggested by Schäfer et al. (2015) for the given cloud base and top altitude $(0-200 \mathrm{~m})$, measurements within a distance of $400 \mathrm{~m}$ to the sea ice edge were removed from the analysis in order to minimize the impact of 3-D-radiative effects at the sea ice edge.

Over sea ice, the retrieved $\tau$ is almost constant with values around 5. Across the sea ice edge, $\tau$ decreases to about 2 and later slightly increases up to $\tau=10$ with increasing distance to the ice edge. The systematic decrease of $\tau$ over the sea ice edge as retrieved by the airborne measurements extends up to $8 \mathrm{~km}$. As indicated by Schäfer et al. (2015), the radiative field across a straight sea ice edge is affected by the surface albedo transition only up to distances of about $400 \mathrm{~m}$. Therefore, the coincidence of the decrease of $\tau$ with the sea ice edge observed here is attributed to the retrieval algorithm but rather has natural causes. It cannot be concluded from this single cross section whether the change of the surface and therefore the change of surface latent and sensible heat fluxes affected the cloud properties across the sea ice edge. As the high-resolution MODIS observations indicate, the cloud field showed an oscillating pattern, which might have coincided with the sea ice edge at the location of the airborne observations.

The retrieved $r_{\text {eff,C }}$ vary slightly more strongly over open water, while the retrieved values over snow-covered sea ice are almost constant at about $r_{\text {eff,C }}=8 \mu \mathrm{m}$ with only short sections of higher cloud droplet sizes. Over open water, larger cloud droplets are found with an average of about $10 \mu \mathrm{m}$. Close to the sea ice edge, until 17:00 UTC, $r_{\text {eff,C }}$ is found to slightly increase with increasing distance to the sea ice edge simultaneously with the increase of $\tau$. The in situ
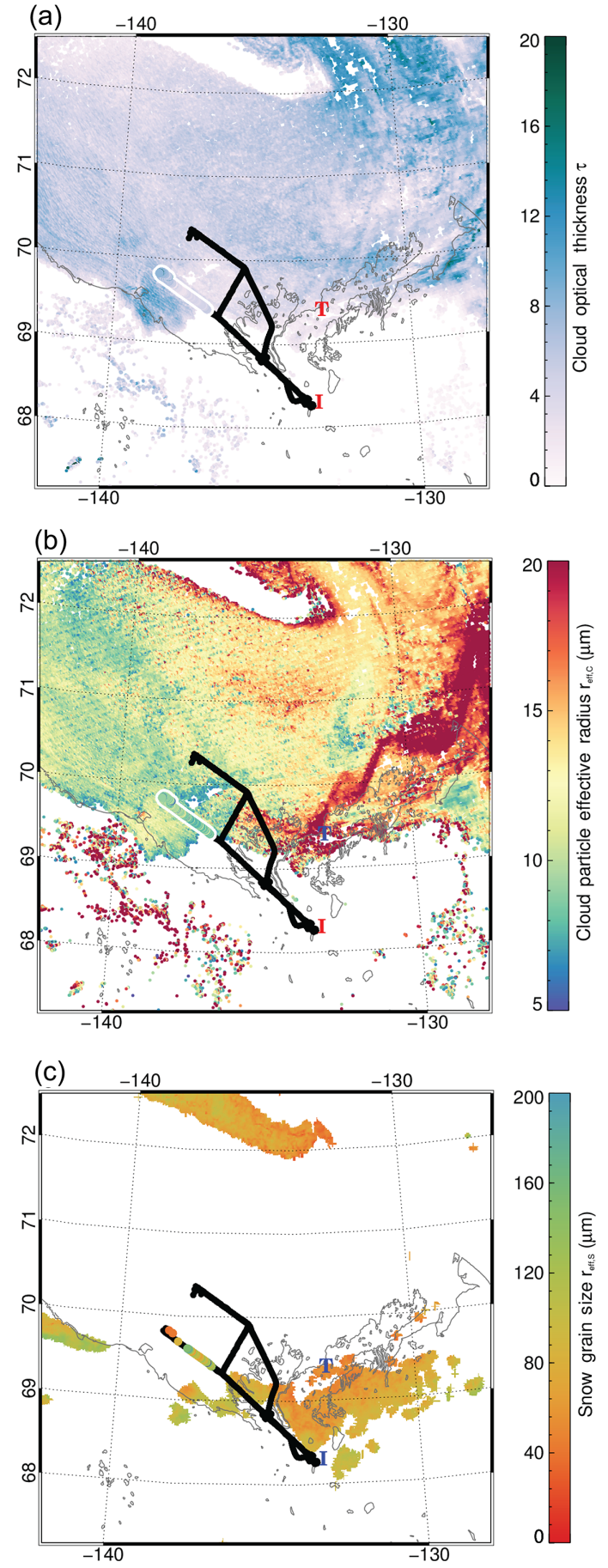

Figure 10. Same as Fig. 8 but for 17 May 2012.

microphysical measurements cover two cloud profiles along the same flight track, one observed above open ocean and one above sea ice. Both profiles showed no difference with $r_{\text {eff,C }}$ of about $9 \mu \mathrm{m}$ at cloud top, which is higher than Case I and in agreement with the retrieval results.

The retrieved $r_{\text {eff,S }}$ shows a slightly higher variability and partly higher values ranging between 50 and $200 \mu \mathrm{m}$ com- 
pared to Case I. The larger snow grains might result from the different location, the advanced time, and snow metamorphism, or the closer location to the open water. For example a systematic decrease of $r_{\mathrm{eff}, \mathrm{S}}$ with distance to the sea ice edge is visible (16:52-16:54 UTC, about $6 \mathrm{~km}$ distance). In Case II the observations take place above compact fast ice without any leads. Photographs from a flight section in the same area below the clouds showed that the fast ice was partly free of snow, which may have caused the higher variability and the single peak of $r_{\mathrm{eff}, \mathrm{S}}=300 \mu \mathrm{m}$.

The comparison of cloud and snow properties retrieved by SMART and MODIS is shown in Fig. 10, similarly to Case I. MODIS results along the flight track are additionally included in Fig. 9. For Case II, the MODIS image was observed at 21:25 UTC, more than $4 \mathrm{~h}$ after the airborne observations. Similarly to Case I, the temporal variation of the cloud properties is expected to be low as stable dynamic conditions in a high-pressure system prevailed during the time of observations and before. Figure 10 shows that the low values of $\tau$ observed by MODIS were also covered by SMART. The slight increase of $\tau$ in the western end of the flight leg is represented by the retrieval using SMART data. A similar pattern and agreement was found for $r_{\text {eff,C }}$.

The direct comparison of the time series in Fig. 9 confirms the general agrement, although differences in the location of cloud fluctuations are obvious. Above sea ice, MODIS observed a steady increase of $\tau$ and $r_{\text {eff,C }}$ and a similar drop at the ice edge as retrieved by SMART. However, a more quantitative comparison of SMART and MODIS cloud products is not possible due to the time difference between the observations. Differences in the retrieved cloud properties may either result from the assumption of snow albedo or from temporal changes of the cloud. Over open water, the MODIS cloud product provided lower $\tau$ and $r_{\text {eff,C. This is }}$ likely caused by the $4 \mathrm{~h}$ difference between both observations. Due to the subsidence in the anticyclonic conditions the cloud top continued to decline and reduced the amount of condensed water, $\tau$, and $r_{\text {eff,C. }}$. The effective snow grain sizes retrieved by SMART are in the range of $r_{\text {eff,S }}$ retrieved by MODIS although the SGSP algorithm could provide results only in small cloud-free areas. The single measurements at the western end of the flight leg indicate that individual ice floes encountered on the ocean and show slightly lower $r_{\text {eff, }}$. This is an indication of fresh snow precipitation in this area where the cloud optical thickness increased.

\section{Conclusions}

The retrieval of cloud properties using spectral reflected solar radiation may be biased significantly if the clouds are located over a snow surface or sea ice. In this case the snow/sea ice properties have to be considered in the retrieval. An inappropriate assumption of the effective snow grain size results in an incorrect surface albedo at near-infrared wavelengths, which imprints in the retrieved cloud optical thickness and droplet effective radius. This snow grain size effect is similar to the retrieval uncertainties reported by Rolland and Liou (2001) and Fricke et al. (2014) for observations over a variable land surface albedo; only that variability of the snow surface albedo is largest at wavelengths above roughly $1000 \mathrm{~nm}$, while the land surface albedo typically varies at wavelengths less than $1000 \mathrm{~nm}$.

For a retrieval of cloud properties using similar wavelengths bands, 1600 and $2100 \mathrm{~nm}$, to those the MODIS cloud product Collection 6 applies for observations over snow or sea ice, the snow grain size effect has been quantified on the basis of radiative transfer simulations. For a typical low-level liquid water cloud $\left(\tau=4, r_{\text {eff, }}=10 \mu \mathrm{m}, \theta_{0}=63^{\circ}\right)$ the retrieved cloud properties would differ by up to $50 \%$ if $r_{\text {eff, }}$ is assumed to be $200 \mu \mathrm{m}$ instead of the original effective snow grain size of $50 \mu \mathrm{m}$, or vice versa. The following is concluded:

- The snow grain size effect is largest for small snow grains because the snow albedo changes more strongly in the range of small $r_{\text {eff,S }}$, while for larger $r_{\text {eff,S }}$ a saturation of the absorption of radiation is reached.

- The snow grain size effect on retrieved $\tau$ is almost independent of cloud optical thickness. At short wavelengths used to retrieve $\tau(\lambda=1600 \mathrm{~nm})$, the snow albedo is still high and always adds to the total reflected radiation. Clouds can not mask this additional reflection of the surface.

- The snow grain size effect on retrieved $r_{\text {eff,C }}$ is strongest for clouds of low optical thickness. At wavelengths used to retrieve $r_{\text {eff,C }}(\lambda=2100 \mathrm{~nm})$ the snow albedo is close to zero. Therefore, in the case of optically thick clouds, the radiation scattered by the clouds dominates and can mask the additional weak reflection of the surface.

- The snow grain size effect on retrieved $\tau$ does not depend on the solar zenith angle, while the effect on $r_{\text {eff,C }}$ is larger for a higher Sun.

To overcome the snow grain size effect, a method is presented that accounts for changes in the snow grain size in the retrieval algorithm for liquid water clouds. A sensitivity study showed that the spectral signatures of cloud and snow properties $\left(\tau, r_{\text {eff, },}, r_{\text {eff,S }}\right)$ significantly differ at specific wavelengths. Three spectral ranges were identified to be most sensitive to the three cloud and snow parameters. At wavelengths between 930 and $1350 \mathrm{~nm}$ the spectral cloud reflectivity is dominated by $r_{\text {eff, }}$, at $1500-1800 \mathrm{~nm}$ by $\tau$, and at $2000-2300 \mathrm{~nm}$ by $r_{\text {eff,C. }}$.

Based on these spectral sensitivities, a retrieval algorithm was designed using reflectivity measurements at $\lambda_{1}=$ $1040 \mathrm{~nm}$ mostly related to $r_{\mathrm{eff}, \mathrm{S}}, \lambda_{2}=1650 \mathrm{~nm}$ related to $\tau$, and $\lambda_{3}=2100 \mathrm{~nm}$ related to $r_{\text {eff,C. }}$. By implementing normal- 
izations in terms of the spectral reflectivity ratios $R_{1}, R_{2}$, and $R_{3}$, the impact of measurement uncertainties was reduced.

The retrieval algorithm was tested in a feasibility study for airborne observations by SMART during VERDI in 2012. Two flight legs, one with closed snow-covered sea ice and a second flown across a snow-covered sea ice edge were analysed. The results and an uncertainty analysis suggest:

- By considering $r_{\text {eff,S }}$, retrieved $\tau$ and $r_{\text {eff,C }}$ are consistent across a sea ice edge where the surface albedo changes from snow-covered sea ice to open water.

- Retrieval uncertainties depend on $\tau$. The thicker the clouds are the stronger they will mask the surface. Less radiation is transmitted into the sub-cloud layer and can be reflected by the surface. This reduces the sensitivity and increases the uncertainties for the retrieval of $r_{\mathrm{eff}, \mathrm{S}}$.

- Retrieval uncertainties also depend on $r_{\text {eff,S }}$. Small $r_{\text {eff,S }}$ increase the snow albedo and reduce the contrast between clouds and snow surface at $\lambda>1000 \mathrm{~nm}$ increasing the uncertainties of $\tau$ and $r_{\text {eff,C. }}$

- Reasonable agreement between in situ cloud microphysical measurement and the MODIS cloud and snow products was found. Differences in the retrieved cloud properties may either result from a wrong assumption of snow albedo or the time difference.

For this first application of the new trispectral retrieval algorithm, a rather simplistic analysis was applied. A more general understanding of the retrieval sensitivities and uncertainties can be achieved by optimal estimation techniques, which is beyond of the scope of this paper. Although the retrieval was applied to cases with a specific solar zenith angle only, radiative transfer simulations showed that the spectral sensitivities used in the retrieval algorithm are similar in the case of smaller or larger solar zenith angles. Therefore, the proposed retrieval method has some potential to be implemented for existing spaceborne imagers such as MODIS or VIIRS. Due to the limited number of spectral bands, for these two instruments $\lambda_{2}$ would have to be exchanged by the $1240 \mathrm{~nm}$ wavelength band where cloud reflectivity is still most sensitive to $r_{\text {eff, } s \text {. }}$

By retrieving cloud properties continuously along transitions from sea ice to open water, the retrieval algorithm allows the impact of surface changes on the cloud microphysical and optical properties to be analysed. However, retrieval results close to such ice edges or in heterogeneous sea ice conditions are influenced by 3-D radiative effects (Schäfer et al., 2015). For the two cases presented here, the cloudbase altitude was low and therefore the 3-D radiative effects were reduced. Only a limited part of the results had to be excluded from the analysis, which is what might differ for clouds located at higher altitudes (Schäfer et al., 2015).

The presented retrieval assumes that the surface albedo can be described by a pure snow layer of sufficient depth with no influence of the sub-snow surface. However, polar sea ice is not always covered by pure snow. Over new sea ice the snow layer might still be thin and the surface albedo reduced by the sub-snow surface (Perovich et al., 2002; Warren, 2013; Malinka et al., 2016). In the melting season, melt ponds change the surface albedo (Grenfell and Perovich, 2004). Locally, melt ponds almost totally absorb solar radiation at wavelengths larger $800 \mathrm{~nm}$ depending on the pond depth (Lu et al., 2016). However, on larger spatial scales, the albedo of melt ponds and snow areas mix into an albedo with spectral features similar to snow of large grains sizes (Istomina et al., 2015). For such cases, it has to be tested whether the proposed retrieval algorithms still improve the estimated cloud properties. However, the spectral signature of white sea ice and melt-pond-covered sea is close to the spectral albedo of pure snow for the wavelengths used in the retrieval. In that case, the retrieved $r_{\text {eff,S }}$ is interpreted as an effective snow grain size representing an arbitrary surface albedo (white sea ice or melt ponds) with the same spectral characteristics above $1000 \mathrm{~nm}$ wavelength as a snow surface with $r_{\text {eff, }}$.

In this study liquid water clouds have been analysed. However, a significant fraction of Arctic clouds are either mixedphase or ice clouds (Mioche et al., 2015). In that case, the retrieval algorithm presented here may provide unrealistic cloud properties. The ice crystals absorb solar radiation at similar wavelengths to the snow surface. Therefore, the information of cloud and surface contribution to the reflected radiation might not be sufficiently separated by the wavelengths applied here. Further sensitivity studies have to be performed to identify a different set of wavelengths that are more appropriate for the remote sensing of ice and mixedphase clouds.

Data availability. All data are available from the authors upon request. For the airborne spectral solar radiation measurements during VERDI contact the University of Leipzig (a.ehrlich@unileipzig.de). The MODIS SGSP product of snow grain size can be made accessible by the University of Bremen, which hosts the SGSP algorithm (lora@iup.physik.uni-bremen.de).

Competing interests. The authors declare that they have no conflict of interest.

Special issue statement. This article is part of the special issue "VERDI - Vertical Distribution of Ice in Arctic Clouds (ACP/AMT inter-journal SI)". It is not associated with a conference.

Acknowledgements. We gratefully acknowledge the support by the SFB/TR 172 "ArctiC Amplification: Climate Relevant Atmospheric and SurfaCe Processes, and Feedback Mechanisms (AC) ${ }^{3}$ " funded by the DFG (Deutsche Forschungsgesellschaft). We thank the Institute for Atmospheric Physic of the Johannes Gutenberg-Universität 
Mainz, in particular Stephan Borrmann and Marcus Klingebiel, for providing the in situ cloud microphysical measurements. We are grateful to the Alfred Wegener Institute Helmholtz Centre for Polar and Marine Research, Bremerhaven, Germany for supporting the VERDI campaign by providing the aircraft and manpower. We would like to thank Kenn Borek Air Ltd., Calgary, Canada for the great pilots who made the complicated measurements possible. For excellent ground support of offices and accommodation during the campaign we are grateful to the Aurora Research Institute, Inuvik, Canada.

Edited by: Patrick Eriksson

Reviewed by: two anonymous referees

\section{References}

Boucher, O., Randall, D., Artaxo, P., Bretherton, C., Feingold, G., Forster, P., Kerminen, V. M., Kondo, Y., Liao, H., Lohmann, U., Rasch, P., Satheesh, S. K., Sherwood, S., B., S., and Zhang, X. Y.: Clouds and Aerosols, in: Climate Change 2013: The Physical Science Basis. Contribution of Working Group I to the Fifth Assessment Report of the Intergovernmental Panel on Climate Change, edited by: Stocker, T. F., Qin, D., Plattner, G. K., Tignor, M., Allen, S. K., Boschung, J., Nauels, A., Xia, V., Bex, V., and Midgley, P. M., book section 7, pp. 571-658, Cambridge University Press, Cambridge, United Kingdom and New York, NY, USA, https://doi.org/10.1017/CBO9781107415324.016, 2013.

Brückner, M., Pospichal, B., Macke, A., and Wendisch, M.: A new multispectral cloud retrieval method for ship-based solar transmissivity measurements, J. Geophys. Res., 119, 11338-11354, https://doi.org/10.1002/2014JD021775, 2014.

Dang, C., Fu, Q., and Warren, S. G.: Effect of snow grain shape on snow albedo, J. Atmos. Sci., 73, 3573-3583, https://doi.org/10.1175/JAS-D-15-0276.1, 2016.

Derksen, C., Lemmetyinen, J., Toose, P., Silis, A., Pulliainen, J., and Sturm, M.: Physical properties of Arctic versus subarctic snow: Implications for high latitude passive microwave snow water equivalent retrievals, J. Geophys. Res., 119, 7254-7270, https://doi.org/10.1002/2013JD021264, 2014.

Ehrlich, A., Bierwirth, E., Wendisch, M., Gayet, J.-F., Mioche, G., Lampert, A., and Heintzenberg, J.: Cloud phase identification of Arctic boundary-layer clouds from airborne spectral reflection measurements: test of three approaches, Atmos. Chem. Phys., 8, 7493-7505, https://doi.org/10.5194/acp-8-7493-2008, 2008.

Emde, C., Buras-Schnell, R., Kylling, A., Mayer, B., Gasteiger, J., Hamann, U., Kylling, J., Richter, B., Pause, C., Dowling, T., and Bugliaro, L.: The libRadtran software package for radiative transfer calculations (version 2.0.1), Geosci. Model Dev., 9, 1647-1672, https://doi.org/10.5194/gmd-9-1647-2016, 2016.

Flanner, M. G. and Zender, C. S.: Linking snowpack microphysics and albedo evolution, J. Geophys. Res., 111, D12208, https://doi.org/10.1029/2005JD006834, 2006.

Fricke, C., Ehrlich, A., Jäkel, E., Bohn, B., Wirth, M., and Wendisch, M.: Influence of local surface albedo variability and ice crystal shape on passive remote sensing of thin cirrus, Atmos. Chem. Phys., 14, 1943-1958, https://doi.org/10.5194/acp14-1943-2014, 2014.
Gao, B. C., Han, W., Tsay, S. C., and Larsen, N. F.: Cloud detection over the Arctic region using airborne imaging spectrometer data during the daytime, J. Appl. Meteorol., 37, 1421-1429, https://doi.org/10.1175/15200450(1998)037<1421:CDOTAR>2.0.CO;2, 1998.

Grenfell, T. C. and Perovich, D. K.: Seasonal and spatial evolution of albedo in a snow-ice-land-ocean environment, J. Geophys. Res., 109, c01001, https://doi.org/10.1029/2003JC001866, 2004.

Herman, G. and Goody, R.: Formation and persistence of summertime arctic stratus clouds, J. Atmos. Sci., 33, 1537-1553, https://doi.org/10.1175/15200469(1976)033<1537:FAPOSA>2.0.CO;2, 1976.

Istomina, L., Heygster, G., Huntemann, M., Schwarz, P., Birnbaum, G., Scharien, R., Polashenski, C., Perovich, D., Zege, E., Malinka, A., Prikhach, A., and Katsev, I.: Melt pond fraction and spectral sea ice albedo retrieval from MERIS data - Part 1: Validation against in situ, aerial, and ship cruise data, The Cryosphere, 9, 1551-1566, https://doi.org/10.5194/tc9-1551-2015, 2015.

Jacobi, H.-W., Domine, F., Simpson, W. R., Douglas, T. A., and Sturm, M.: Simulation of the specific surface area of snow using a one-dimensional physical snowpack model: implementation and evaluation for subarctic snow in Alaska, The Cryosphere, 4, 35-51, https://doi.org/10.5194/tc-4-35-2010, 2010.

King, M. D., Platnick, S., Yang, P., Arnold, G. T., Gray, M. A., Riedi, J. C., Ackerman, S. A., and Liou, K. N.: Remote sensing of liquid water and ice cloud optical thickness and effective radius in the Arctic: Application of airborne multispectral MAS data, J. Atmos. Ocean. Technol., 21, 857-875, 2004.

Klingebiel, M., de Lozar, A., Molleker, S., Weigel, R., Roth, A., Schmidt, L., Meyer, J., Ehrlich, A., Neuber, R., Wendisch, M., and Borrmann, S.: Arctic low-level boundary layer clouds: in situ measurements and simulations of mono- and bimodal supercooled droplet size distributions at the top layer of liquid phase clouds, Atmos. Chem. Phys., 15, 617-631, https://doi.org/10.5194/acp-15-617-2015, 2015.

Krijger, J. M., Tol, P., Istomina, L. G., Schlundt, C., Schrijver, H., and Aben, I.: Improved identification of clouds and ice/snow covered surfaces in SCIAMACHY observations, Atmos. Meas. Tech., 4, 2213-2224, https://doi.org/10.5194/amt-4-2213-2011, 2011.

LeBlanc, S. E., Pilewskie, P., Schmidt, K. S., and Coddington, O.: A spectral method for discriminating thermodynamic phase and retrieving cloud optical thickness and effective radius using transmitted solar radiance spectra, Atmos. Meas. Tech., 8, 1361-1383, https://doi.org/10.5194/amt-8-1361-2015, 2015.

Libois, Q., Picard, G., France, J. L., Arnaud, L., Dumont, M., Carmagnola, C. M., and King, M. D.: Influence of grain shape on light penetration in snow, The Cryosphere, 7, 1803-1818, https://doi.org/10.5194/tc-7-1803-2013, 2013.

Liou, K. N., Takano, Y., He, C., Yang, P., Leung, L. R., Gu, Y., and Lee, W. L.: Stochastic parameterization for light absorption by internally mixed BC/dust in snow grains for application to climate models, J. Geophys. Res., 119, 7616-7632, https://doi.org/10.1002/2014JD021665, 2014.

Lu, P., Leppäranta, M., Cheng, B., and Li, Z.: Influence of melt-pond depth and ice thickness on Arctic sea-ice albedo and light transmittance, Cold Reg. Sci. Technol., 124, 1-10, https://doi.org/10.1016/j.coldregions.2015.12.010, 2016. 
Lyapustin, A., Tedesco, M., Wang, Y., Aoki, T., Hori, M., and Kokhanovsky, A.: Retrieval of snow grain size over Greenland from MODIS, Remote Sens. Environ., 113, 1976-1987, https://doi.org/10.1016/j.rse.2009.05.008, 2009.

Malinka, A., Zege, E., Heygster, G., and Istomina, L.: Reflective properties of white sea ice and snow, The Cryosphere, 10, 25412557, https://doi.org/10.5194/tc-10-2541-2016, 2016.

Mioche, G., Jourdan, O., Ceccaldi, M., and Delanoë, J.: Variability of mixed-phase clouds in the Arctic with a focus on the Svalbard region: a study based on spaceborne active remote sensing, Atmos. Chem. Phys., 15, 2445-2461, https://doi.org/10.5194/acp15-2445-2015, 2015.

Nakajima, T. and King, M.: Determination of the optical thickness and effective particle radius of clouds from reflected solar radiation measurements. Part I: Theory, J. Atmos. Sci., 47, 18781893, 1990.

Painter, T. H., Rittger, K., McKenzie, C., Slaughter, P., Davis, R. E., and Dozier, J.: Retrieval of subpixel snow covered area, grain size, and albedo from MODIS, Remote Sens. Environ., 113, 868879, https://doi.org/10.1016/j.rse.2009.01.001, 2009.

Perovich, D. K., Grenfell, T. C., Light, B., and Hobbs, P. V.: Seasonal evolution of the albedo of multiyear Arctic sea ice, J. Geophys. Res., 107, 8044, https://doi.org/10.1029/2000JC000438, 2002.

Pilewskie, P. and Twomey, S.: Discrimination of ice from water in clouds by optical remote sensing, Atmos. Res., 21, 113-122, 1987.

Platnick, S.: Approximations for horizontal photon transport in cloud remote sensing problems, J. Quant. Spectrosc. Ra., 68, 7599, 2001.

Platnick, S., Ackerman, S. A., Baum, B. A., Heidinger, A. K., Holz, R. E., King, M. D., Menzel, W. P., Nasiri, S., Weisz, E., and Yang, P.: Assessment of IDPS VIIRS cloud products and recommendations for EOS-era cloud climate data record continuity, Tech. Rep., p. 57, NASA Goddard Space Flight Center, Greenbelt, MD, USA, available at: http://library.ssec.wisc.edu/research_Resources/publications/ pdfs/SSECPUBS/SSEC_Publication_No_13_03_B1.pdf (last access: August 2017), 2013.

Platnick, S., Meyer, K. G., King, M. D., Wind, G., Amarasinghe, N., Marchant, B., Arnold, G. T., Zhang, Z., Hubanks, P. A., Holz, R. E., Yang, P., Ridgway, W. L., and Riedi, J.: The MODIS cloud optical and microphysical products: Collection 6 updates and examples from Terra and Aqua, IEEE Trans. Geosci. Remote Sens., 55, 502-525, https://doi.org/10.1109/TGRS.2016.2610522, 2017.

Rolland, P. and Liou, K.: Surface variability effects on the remote sensing of thin cirrus optical and microphysical properties, J. Geophys. Res., 106, 22965-22977, https://doi.org/10.1029/2001JD900160, 2001.

Schäfer, M., Bierwirth, E., Ehrlich, A., Jäkel, E., and Wendisch, M.: Airborne observations and simulations of three-dimensional radiative interactions between Arctic boundary layer clouds and ice floes, Atmos. Chem. Phys., 15, 8147-8163, https://doi.org/10.5194/acp-15-8147-2015, 2015.

Shupe, M. D., Matrosov, S. Y., and Uttal, T.: Arctic mixed-phase cloud properties derived from surface-based sensors at SHEBA, J. Atmos. Sci., 63, 697-711, 2006.
Shupe, M. D., Walden, V. P., Eloranta, E., Uttal, T., Campbell, J. R., Starkweather, S. M., and Shiobara, M.: Clouds at Arctic atmospheric observatories. Part I: Occurrence and macrophysical properties, J. Appl. Meteorol., 50, 626-644, https://doi.org/10.1175/2010JAMC2467.1, 2011.

Singh, P.: Snow and glacier hydrology, water science and technology library, Springer Netherlands, 1 edn., ISBN: 978-90-4815635-1, 2001.

Stephens, G. L. and Kummerow, C. D.: The remote sensing of clouds and precipitation from space: A review, J. Atmos. Sci., 64, 3742-3765, 2007.

Vaughan, D., Comiso, J., Allison, I., Carrasco, J., Kaser, G., Kwok, R., Mote, P., Murray, T., Paul, F., Ren, J., Rignot, E., Solomina, O., Steffen, K., and Zhang, T.: Observations: Cryosphere, in: Climate Change 2013: The Physical Science Basis. Contribution of Working Group I to the Fifth Assessment Report of the Intergovernmental Panel on Climate Change, edited by: Stocker, T. F., Qin, D., Plattner, G.-K., Tignor, M., Allen, S. K., Boschung, J., Nauels, A., Xia, Y., Bex, V., and Midgley, P. M., book section 4, 317-382, Cambridge University Press, Cambridge, United Kingdom and New York, NY, USA, https://doi.org/10.1017/CBO9781107415324.012, 2013.

Warren, S. and Wiscombe, W.: A model for the spectral albedo of anow. II: Snow containing atmospheric aerosols, J. Atmos. Sci., 37, 2734-2745, 1980.

Warren, S. G.: Can black carbon in snow be detected by remote sensing?, J. Geophys. Res., 118, 779-786, https://doi.org/10.1029/2012JD018476, 2013.

Warren, S. G. and Brandt, R. E.: Optical constants of ice from the ultraviolet to the microwave: A revised compilation, J. Geophys Res., 113, D14220, https://doi.org/10.1029/2007JD009744, 2008.

Wendisch, M., Müller, D., Schell, D., and Heintzenberg, J.: An airborne spectral albedometer with active horizontal stabilization, J. Atmos. Ocean. Technol., 18, 1856-1866, 2001.

Wendisch, M., Brückner, M., Burrows, J. P., Crewell, S., Dethloff, K., Ebell, K., Lüpkes, C., Macke, A., Notholt, J., Quaas, J., Rinke, A., and Tegen, I.: Understanding causes and effects of rapid warming in the Arctic, Eos, 98, 22-26, https://doi.org/10.1029/2017EO064803, 2017.

Werner, F., Siebert, H., Pilewskie, P., Schmeissner, T., Shaw, R. A., and Wendisch, M.: New airborne retrieval approach for trade wind cumulus properties under overlying cirrus, J. Geophys. Res.-Atmos., 118, 3634-3649, https://doi.org/10.1002/jgrd.50334, 2013.

Wiebe, H., Heygster, G., Zege, E., Aoki, T., and Hori, M.: Snow grain size retrieval SGSP from optical satellite data: Validation with ground measurements and detection of snow fall events, Remote Sens. Environ., 128, 11-20, https://doi.org/10.1016/j.rse.2012.09.007, 2013.

Wiscombe, W. and Warren, S.: A model for the spectral albedo of snow I. Pure snow, J. Atmos. Sci., 37, 2712-2733, 1980.

Zege, E. P., Katsev, I. L., Malinka, A. V., Prikhach, A. S., Heygster, G., and Wiebe, H.: Algorithm for retrieval of the effective snow grain size and pollution amount from satellite measurements, Remote Sens. Environ., 115, 2674-2685, https://doi.org/10.1016/j.rse.2011.06.001, 2011. 